\title{
Voto econômico retrospectivo e sofisticação política na eleição presidencial de 2002
}

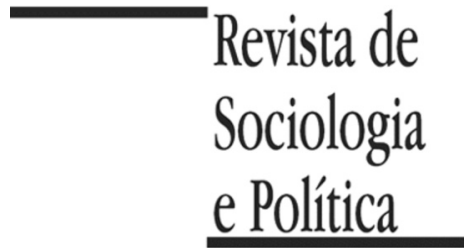

DOI: $10.1590 / 1678-987314225010$

\author{
Frederico Batista Pereira
}

\section{RESUMO}

Este artigo aborda o tema do voto econômico a partir da perspectiva da desigualdade de sofisticação política entre os eleitores. Diversos estudos mostram que os eleitores brasileiros tendem a se basear na economia para votar e avaliar os presidentes. Essas evidências algumas vezes servem de suporte para a afirmação de que, mesmo não utilizando os partidos, os rótulos ideológicos e outras questões politicamente relevantes como referências para suas escolhas, o eleitorado de massa no Brasil seria capaz de tomar decisões criteriosas na política. Utilizando dados de pesquisa de painel coletados ao longo de 2002 em Caxias do Sul e Juiz de Fora, o artigo testa até que ponto o efeito da avaliação retrospectiva da economia (tanto do país quanto pessoal) sobre o voto para presidente depende do nível de sofisticação política do respondente. Os resultados mostram que a avaliação da economia tende a ser uma opinião instável ao longo do período analisado, e tem impacto sobre a escolha do candidato a presidente apenas entre os eleitores mais politicamente sofisticados. As implicações dos achados são discutidas e aponta-se para a relevância de se levar em conta o impacto da desigualdade de sofisticação política entre os eleitores no entendimento da dinâmica das eleições e da opinião pública no Brasil.

PALAVRAS-CHAVE: voto econômico; avaliação retrospectiva; sofisticação política; eleições; competência cívica.

Recebido em 18 de Junho de 2012. Aprovado em 12 de Novembro de 2012.

\section{Introdução ${ }^{1}$}

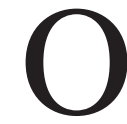
s estudos eleitorais mais recentes no Brasil têm buscado um determinante do voto para presidente que seja capaz de explicar de que maneira o eleitorado popular escolhe seus candidatos a presidente. Se o eleitor mediano parece não votar com base em vínculos afetivos de longa duração com os partidos, se desconhece os termos "direita" e "esquerda", e também não conecta outras opiniões políticas com seu voto para presidente, com base em que se pode dizer esse eleitor escolhe seu candidato a presidente?

A perspectiva do voto econômico parece oferecer uma resposta a essa pergunta e vem ganhando destaque na literatura. Diversos achados, que se acumulam desde as eleições presidenciais da década de 1990, parecem dar suporte à ideia de que o eleitorado brasileiro se guiaria pela economia. Acerca do pleito de 1994, por exemplo, estudos com base em dados de pesquisas de opinião mostram que a avaliação positiva do Plano Real estaria associada ao voto no candidato Fernando Henrique Cardoso (Mendes \& Venturi 1994; Meneguello 1996). Outros trabalhos também fornecem evidências com base em dados de survey sobre o efeito da avaliação econômica dos eleitores sobre sua decisão de voto na eleição presidencial de 1998 (Camargos 1999; Carreirão 1999). No que se refere a 2002, alguns trabalhos também mostram que a avaliação do desempenho do governo de Fernando Henrique Cardoso estaria associada ao voto para presidente, tendo impacto sobre os votos em José Serra e Lula (Car- 
reirão 2004; 2007; Carreirão \& Barbetta 2004; Nicolau 2007). No caso das eleições presidenciais de 2006, estudos baseados em dados agregados mostram que, diferentemente do que ocorrera em 2002, quando Lula recebeu proporções de votos homogeneamente distribuídas nas diferentes regiões do país, sua votação tendeu a ser muito maior nas regiões mais pobres, especialmente o Nordeste, onde há maior proporção de beneficiários do programa Bolsa Família (Nicolau \& Peixoto 2007; Hunter \& Power 2007; Soares \& Terron 2008). Outros estudos testam, também por meio da análise de dados agregados, se os padrões regionais de votação em Lula se deveriam à economia, isto é, se as regiões mais pobres do país não seriam também as mais beneficiadas com o retrospecto econômico favorável do primeiro mandato de Lula (Shikida et al. 2009), ou por serem mais dependentes de recursos provenientes do governo federal (Zucco 2008). Além desses achados, o estudo de Licio, Rennó e Castro (2009) utiliza dados de survey e verifica um efeito positivo do programa Bolsa Família sobre o voto e sobre a avaliação do desempenho do governo Lula.

No entanto, ainda que essa literatura tenha méritos indiscutíveis, não há evidências sistemáticas sobre se o fenômeno do voto econômico caracteriza tipicamente o comportamento dos eleitores brasileiros menos sofisticados. As associações estatísticas encontradas por esses estudos referem-se à totalidade do eleitorado e, portanto, não informam até que ponto os resultados caracterizam o comportamento de certos subgrupos das amostras analisadas. Partindo dessa lacuna, o presente artigo explora o efeito condicional da sofisticação política sobre o chamado voto econômico. A premissa teórica é a de que eleitores com diferentes níveis de sofisticação política processam de formas distintas os estímulos do ambiente eleitoral, de modo que as orientações dos eleitores mais sofisticados tendem a ser baseadas em conjuntos mais amplos e consistentes de informações, sendo, por essa razão, mais efetivas em terem impacto sobre outras orientações e comportamentos (Sniderman, Brody \& Tetlock 1991; Zaller 1992). Sendo assim, o principal objetivo do artigo é averiguar se a sofisticação política é uma condição para o voto econômico, isto é, se é preciso que um eleitor seja politicamente sofisticado para que vote economicamente. Se eleitores com níveis distintos de sofisticação política têm a mesma probabilidade de votarem economicamente, ou mesmo se os menos sofisticados são mais propensos a fazê-lo, então os achados da literatura anterior podem ser interpretados como um diagnóstico adequado sobre a qualidade da representação eleitoral no Brasil. Por outro lado, caso o voto econômico caracterize apenas o comportamento de eleitores mais politicamente sofisticados, a ideia de que a representação política dos menos sofisticados ocorre devido ao fato de que tais eleitores votam com base na economia precisará ser revista.

Na próxima seção discute-se a articulação teórica entre duas perspectivas supostamente opostas, mas que têm sido continuamente aproximadas na Ciência Política internacional: a do voto econômico e a da sofisticação política. $\mathrm{Na}$ terceira seção aborda-se as hipóteses e os mecanismos causais mais específicos relacionados ao efeito condicional da sofisticação política sobre o voto econômico, bem como a relevância da teoria da sofisticação política para a produção corrente acerca do voto econômico no Brasil. Na quarta seção descreve-se os dados e os métodos utilizados no artigo. Por fim, apresenta-se e discute-se os resultados das análises empíricas. 


\section{Racionalidade, voto econômico e sofisticação política}

${ }^{2}$ Para uma revisão comparativa entre os trabalhos de Downs e Key, ver Fiorina (1981).

\footnotetext{
${ }^{3}$ Uma leitura cuidadosa de Downs, no entanto, permite notar que a tensão entre a falta de informação e o voto econômico também já se acena na obra desse autor. Downs sugere que eleitores racionais podem ter incentivos para manterem-se desinformados caso o custo de adquirirem novas informações seja alto. Ao mesmo tempo, o autor defende que essas
}

O chamado voto econômico constitui uma escolha individual discreta na qual os indivíduos atribuem valores às alternativas políticas (candidatos e/ou partidos) com base em suas avaliações do desempenho econômico do país, estado, ou qualquer outro nível de governo (Duch \& Stevenson 2008, p. 42). Além disso, também é possível que os indivíduos tenham como referência diferentes períodos de tempo ao emitirem suas avaliações (Lewis-Beck 1985). Eleitores podem avaliar retrospectiva ou prospectivamente o desempenho da economia, ou podem simplesmente levar em consideração a presente situação sem qualquer referência a passado ou futuro. Além do mais, ainda que a definição dada acima focalize apenas o desempenho econômico de coletividades (tal avaliação também é chamada de "sociotrópica"), parte da literatura também inclui na rubrica "voto econômico" o ato de basear a escolha na avaliação da situação econômica pessoal.

Seja como for, cabe observar que na definição acima a ideia de voto econômico não tem vínculo conceitual necessário com nenhuma tradição teórica específica da Ciência Política. Uma noção muito disseminada entre estudiosos do fenômeno eleitoral é a de que o conceito de voto econômico deriva de certas versões da abordagem da escolha racional. Apesar de ainda encontrar muitos adeptos, essa visão é apenas parcialmente correta. Por um lado, não há dúvidas de que um dos trabalhos fundadores do campo de estudos do voto econômico é o clássico livro de Downs (1957). Por outro lado, paralelamente a Downs, outros estudiosos abordaram o voto econômico sem necessariamente prestarem tributos à escolha racional. O trabalho de Key (1966) sobre as eleições presidenciais estadunidenses entre 1936 e 1960, um dos primeiros na área, não apresenta filiação à abordagem em questão ${ }^{2}$. Sendo assim, é enganosa a visão de que o voto econômico constitui um fenômeno sobre o qual a abordagem da escolha racional tenha exclusividade, tanto pela diversidade de tradições teóricas que compõem os trabalhos fundadores do campo, quanto pelo crescente diálogo e intercâmbio entre tais tradições na literatura mais atual.

No trabalho de Key (idem), inclusive, já se insinua o afastamento do solipsismo teórico e epistemológico no estudo do voto econômico em favor da articulação entre elementos de abordagens distintas. Um dos principais argumentos do autor é o de que o eleitorado estadunidense não seria tão alheio à política quanto descreveram os autores da escola de Michigan (Campbell et al. 1960; Converse 1964). Segundo Key, mesmo não apresentando altos níveis de interesse e conhecimento sobre política, o eleitorado estadunidense seria capaz de punir ou recompensar candidatos tendo como referência o desempenho da economia. Nesse sentido, a conexão entre o estudo sobre o que os cidadãos sabem sobre política - um tema caro à escola de Michigan - e sua capacidade de votar economicamente constitui a base do trabalho pioneiro de Key sobre o voto econômico ${ }^{3}$.

Seguindo a trilha deixada por Key, tanto a literatura mais recente da escolha racional quanto estudiosos de psicologia política têm se esforçado para integrar o estudo do voto econômico à temática do conhecimento ou sofisticação política. Na Ciência Política estadunidense, por exemplo, uma variedade de estudos empíricos fornece evidências de que a sofisticação política é uma variável crucial para o entendimento da dinâmica do voto econômico. O clássico estudo de Fiorina (1981) mostra, entre outras coisas, que a avaliação da economia se conectaria mais sistematicamente com o voto na medida em que 
informações sejam necessárias para que o eleitor diferencie e escolha os candidatos/partidos. Nesse sentido, o próprio estudo de Downs já aponta para a agenda de pesquisa que articule o voto econômico com o problema da informação (Aidt 2000). aumentam os níveis de escolaridade, interesse por política e exposição às informações políticas (idem, pp. 49-56). O estudo de Howell (1986), por exemplo, mostra que a percepção da economia tende a ser uma opinião mais instável entre eleitores menos politicamente sofisticados do que entre eleitores mais sofisticados. Consequentemente, verifica-se que os menos sofisticados tenderiam a basear-se nas preferências que teriam pelos candidatos ao emitirem julgamentos sobre o desempenho da economia do país, isto é, seu voto afetaria sua avaliação da economia, e não o contrário. Mutz (1993) também verifica que o nível de sofisticação política dos eleitores tenderia a aumentar o efeito da avaliação da situação econômica pessoal sobre suas preferências políticas. Alguns trabalhos importantes entre os estudos comparativos sobre o voto econômico também abordam, sob diferentes ângulos, o efeito da desigualdade de sofisticação política em vários contextos (Duch 2001; Godbout \& Bélanger 2007; Gomez \& Wilson 2006). Por fim, trabalhos recentes na própria literatura mais especializada da escolha racional também já incorporam a desigualdade de informação a modelos formais que visam a explicar a lógica do voto econômico (Aidt 2000). Curiosamente, muito embora a literatura tenha seguido a tendência iniciada por Key em busca de articular o estudo do problema da sofisticação dos eleitores ao tema do voto econômico, as conclusões às quais chegam os principais trabalhos nessa linha sugerem que a objeção do autor à escola de Michigan não se sustente empiricamente. Ao que tudo indica, é preciso ser minimamente sofisticado para votar-se economicamente.

A articulação entre abordagens distintas no estudo do voto tampouco é novidade na Ciência Política brasileira. Os trabalhos de Reis $(1988 ; 1991 ; 2000)$ já propunham a articulação entre tradições distintas no estudo do comportamento político, com especial ênfase em uma concepção mais ampla da racionalidade. Reis sugere que a racionalidade seja entendida não por referência aos fins específicos buscados pelos indivíduos, tal como propunham certas versões mais ortodoxas da escolha racional, mas antes como a característica da ação voltada para maximizar tais fins (Reis 2000, pp. 116-117). Nesse sentido, fins de natureza econômica ou egoísta não seriam mais racionais do que fins qualquer outro tipo: "o racional para o altruísta é agir altruisticamente" (idem, p. 114). Ainda segundo Reis, seria possível falar em graus de "racionalidade" por referência ao volume de informações processadas pelo agente (Reis 1991, pp. 36-37). Partindo dessa concepção, a tarefa do analista da ação seria a de reconstruir a racionalidade dos agentes levando em conta os diferentes níveis de informação e os diferentes contextos nos quais esses últimos se encontram (idem, p. 36). Essa orientação fica clara quando, ao analisar dados de Belo Horizonte durante o período militar, o autor conclui: "[...] os próprios dados acima analisados indicam bastante claramente os elementos de desinformação e alheamento com respeito a aspectos importantes da conjuntura sócio-econômica e política do país que se associam às preferências expressas pelo eleitorado, destacando-se, por exemplo, a reduzida saliência de questões propriamente políticas entre os eleitores de diferentes camadas sociais ou preferências partidárias, o grande desconhecimento de temas de relevância óbvia no debate político atual e o fato de que mesmo questões de natureza sócio-econômica, ainda que figurem de maneira bastante mais nítida na consciência dos eleitores, apenas mostrem alguma relação com o voto ou a preferência pelo partido de oposição entre as camadas sociais comparativamente elevadas, apesar de que o apoio ao MDB provenha sobretudo dos níveis sociais mais baixos" (Reis 1975, p. 148). 
Alguns estudos no Brasil mostram a mesma orientação no sentido de se levar em conta as desigualdades no eleitorado. A tese de Castro (1994) sobre a relevância da sofisticação política é certamente um marco nos estudos eleitorais no Brasil. Nela a autora mostra, entre outras coisas, como o eleitorado é estratificado no que se refere à sofisticação política, e de que maneira eleitores com níveis distintos de sofisticação utilizam os determinantes clássicos do voto de formas diferentes. Destaca-se, no trabalho, a evidência de que eleitores menos sofisticados tendem a atribuir aos candidatos preferidos suas opiniões sobre assuntos políticos diversos, mesmo quando os candidatos são claramente distantes de tal posição do ponto de vista ideológico. Carreirão (2002), por sua vez, mostra que a auto-localização no eixo "direita-esquerda" apenas afetaria o voto para presidente entre eleitores mais escolarizados, o que também corrobora a posição previamente defendida por Reis (1975). O trabalho mais recente de Turgeon e Rennó (2010) mostra que a desigualdade de informação política no eleitorado brasileiro também afetaria drasticamente a distribuição das opiniões sobre impostos e gastos governamentais.

No que se refere à discussão sobre o efeito das avaliações econômicas sobre o voto no Brasil, prevalece certa visão, nos discursos popular e acadêmico, de que o eleitorado menos sofisticado tende a votar economicamente, ainda que não haja claras evidências empíricas que sustentem tal afirmação. Nesse sentido, o desenvolvimento que se esboça nas pesquisas sobre outros determinantes do voto não se manifesta no campo de estudos do voto econômico. Fazse necessário, portanto, articular a perspectiva da sofisticação política com a temática do voto econômico no contexto brasileiro. Em busca desse objetivo, a próxima seção discute mais detalhadamente os efeitos possíveis da sofisticação política sobre a capacidade do eleitor de conectar suas avaliações da economia à decisão do voto. Além disso, argumenta-se que as análises do voto econômico que não levam em conta a desigualdade de sofisticação política entre os eleitores ignoram aspectos teóricos e normativos importantes para o debate sobre o voto econômico.

\section{Os requisitos cognitivos do voto econômico e o problema da agregação}

Quando uma pessoa responde a uma pergunta sobre a situação da economia em uma pesquisa de opinião, leva em conta algumas das considerações ou informações que tem sobre o assunto. As considerações das quais as pessoas recordam-se ao avaliarem a situação da economia, do país ou do próprio lar, podem variar em conteúdo e em quantidade. Se a pessoa tem mais considerações positivas do que negativas estocadas na memória, provavelmente emitirá um julgamento positivo sobre o objeto que avalia. Caso contrário, terá algo negativo a dizer (Zaller 1992, p. 40; Zaller \& Feldman 1992, p. 585).

Entretanto, para que uma pessoa conecte sua avaliação da economia do país e seu voto para presidente são necessários requisitos adicionais. Primeiramente, deve-se eleger pelo menos um indicador do desempenho econômico do país. É preciso identificar um ou mais indicadores de bom ou mau desempenho econômico, que podem variar desde a prosperidade da própria vizinhança até os indicadores do Banco Mundial sobre o desempenho econômico do país. Um segundo requisito é que o indivíduo seja capaz de identificar a conexão entre o indicador de desempenho econômico e a política do país. Ou seja, é necessário que o indivíduo também saiba que aquele aspecto da economia que leva consideração depende de decisões dos líderes políticos. Um terceiro passo é que o indivíduo seja capaz de responsabilizar algum dos candidatos ou partidos que 
disputam a eleição pelos resultados econômicos avaliados. Dessa forma, caso veja o mandatário do governo federal como responsável pelo bom ou mau desempenho da economia, aumenta-se a probabilidade de que relacione a escolha de seu candidato à presidência com tal avaliação. Os requisitos são análogos quando se trata da avaliação retrospectiva pessoal.

Tendo em vista a listagem de requisitos para que a avaliação retrospectiva (sociotrópica ou pessoal) tenha efeito sobre o voto, pode-se dizer que a probabilidade de que isso ocorra varia de indivíduo para indivíduo. Faz-se necessário, portanto, que o ambiente forneça estímulos claros que indiquem para eleitor os fatores com base nos quais ele pode "politizar" sua avaliação da economia, e também que o eleitor tenha o mínimo de habilidade para reconhecer tais estímulos e ter seu comportamento influenciado por eles.

As análises do efeito da avaliação retrospectiva da economia sobre o voto no Brasil não chegam a abordar o problema da efetividade de tal determinante levando em conta a desigualdade de sofisticação política. Por sofisticação política compreende-se aqui a quantidade de informações políticas de um indivíduo, bem como sua capacidade de processá-las (Luskin 1990, p. 332; Neuman 1981, p. 1 237). Obviamente, a sofisticação não se distribui aleatoriamente na população. Ela está associada ao posicionamento dos cidadãos em relação ao sistema sócio-político, se possuem mais ou menos renda, escolaridade, além de estar associada a variáveis sócio-demográficas como sexo, idade e raça. Além de tais atributos "objetivos", estariam sistematicamente associados à sofisticação política aspectos mais "subjetivos" como o interesse por política e a exposição à informação em meios de comunicação (Delli Carpini \& Keeter 1996; Luskin 1990). Estudos no Brasil mostram que algumas dessas variáveis estariam sistematicamente associadas aos níveis de sofisticação entre eleitores brasileiros (Fuks \& Batista Pereira 2011; Rennó 2007; Reis \& Castro 1992). De todo modo, a desigualdade de sofisticação política parece ter pelo menos duas consequências importantes para a análise do efeito das percepções da economia. Em primeiro lugar, uma vez que a sofisticação implica que certos indivíduos tenham maior estoque de considerações sobre os assuntos, o que aumenta a probabilidade de que tenham opiniões estáveis (Zaller \& Feldman 1992), é possível que os mais sofisticados tenham também percepções mais estáveis e consistentes a respeito da economia do que os menos sofisticados. Segundo, quanto mais politicamente sofisticado é um indivíduo, maior é a probabilidade de que ele tenha informações básicas que são necessárias para o voto econômico, como, por exemplo, qual o nível de governo responsável por certos resultados econômicos, ou até sobre quais dos candidatos da disputa representam a situação e a oposição. Sendo assim, a sofisticação política está direta e positivamente relacionada a requisitos informacionais e atitudinais mínimos para que os cidadãos votem economicamente.

Por outro lado, apesar de certo nível mínimo de sofisticação política ser necessário para que o eleitor vote com base na economia, há também razões para supor-se que, em certas circunstâncias, eleitores mais sofisticados importem-se menos com a economia do que eleitores menos sofisticados. Duch e Stevenson (2008) fornecem razões para que eleitores informados deixem de conectar a economia à decisão do voto. Eleitores mais sofisticados tendem a desenvolver percepções mais nuançadas a respeito da política do país e de sua relação com a política internacional. É possível que eleitores suficientemente informados para estabelecer a conexão entre economia e voto deixem de fazêlo por considerarem que a responsabilidade pelos resultados da economia não se concentra exclusivamente no partido ou no chefe governo. Em certas cir- 
${ }^{4}$ Para perspectivas mais matizadas a respeito do assunto, ver $\mathrm{Ar}-$ ceneux e Stein (2006), e Rennó e Gramacho (2010).
${ }^{5}$ A falácia ecológica ocorre quando as correlações entre variáveis individuais coletadas no nível de agregados de indivíduos não se verificam quando analisadas no nível propriamente individual (Robinson 1950). cunstâncias, especialmente em governos onde há maior distribuição das atribuições entre diferentes partidos e grupos, há razões para que o cidadão mais sofisticado deixe de responsabilizar exclusivamente um candidato específico pela situação da economia (Gomez \& Wilson 2008) ${ }^{4}$. Além disso, os eleitores mais sofisticados podem também levar em conta o impacto de fatores que em alguma medida escapam ao controle dos governantes, e que têm a ver com a dinâmica do mercado internacional (Anderson 2006). Por fim, outra razão mais simples pela qual os eleitores mais politicamente sofisticados podem simplesmente ignorar a economia ao votarem é a de que eles são justamente os mais propensos a basearem-se nas clivagens partidárias e ideológicas do sistema político (Delli Carpini \& Keeter 1996). Isso implica que provavelmente parte dos eleitores mais sofisticados já possui uma escolha definida antes mesmo de considerar como vai a economia.

Sendo assim, há razões conflitantes a respeito do impacto da sofisticação política sobre o voto econômico retrospectivo. De todo modo, o que as conjecturas acima tratam de elucidar é justamente o ponto defendido pela teoria da interação da sofisticação política: eleitores com diferentes níveis de complexidade na apreensão do universo político comportam-se de formas distintas, isto é, guiados por informações e estímulos distintos. Portanto, qualquer generalização a respeito dos determinantes do voto (ou do comportamento político de maneira mais geral) que desconsidere a desigualdade de sofisticação política entre os eleitores corre o risco de ser irrealista, uma vez que trata de um eleitor hipotético que não caracteriza adequadamente nenhum dos cidadãos no sistema político.

Portanto, ao ignorar a desigualdade de sofisticação política entre os eleitores, perde-se de vista variações individuais que podem ser teoricamente relevantes, por conta do problema da "agregação física" das análises (Luskin 2002). Vale enfatizar que não se trata aqui exclusivamente da diferença entre análises que utilizam dados coletados no nível de agregados coletivos (como zonas eleitorais, por exemplo) e dados coletados no nível dos indivíduos. É comum nas análises do comportamento político que usam dados de nível individual a alegação de que a grande vantagem desse tipo de material seria a superação do risco da "falácia ecológica"5. Com efeito, é sempre preferível dispor de dados coletados no nível dos indivíduos quando se trata de analisar relações entre atributos individuais. Todavia, a ênfase no problema da "falácia ecológica" deixa na sombra outro problema relacionado a agregação.

Luskin (idem, p. 225) argumenta que, do ponto de vista das diferenças de especificação entre modelos lineares, os dados individuais apresentariam uma vantagem clara em relação aos dados agregados em um aspecto que teria ligação apenas indireta com o problema da "falácia ecológica". Um modelo linear aditivo simples para dados de nível individual pode ser ilustrado na equação abaixo:

$$
y_{i}=\beta_{0}+\beta_{1} x_{1}+u_{i}
$$

Já para os dados agregados, a especificação do modelo linear muda um pouco, como mostra Luskin. Utilizando-se o somatório dos termos nos dois lados da equação e dividindo-se cada termo pelo número de observações na análise, obtém-se o seguinte: 
${ }^{6}$ A omissão dos efeitos isolados de cada uma das variáveis independentes serve apenas para simplificar a exposição do argumento.

$$
\bar{y}_{g}=\beta_{0}+\beta_{1} \bar{x}_{g}+\bar{u}_{g}
$$

Na equação dos dados agregados, as variáveis e o termo de erro são representados pelas médias de cada agregado $g$ analisado. O que se observa é que os dois modelos são praticamente iguais, com a diferença de que os resíduos do modelo de dados individuais tendem a ser homocedásticos (distribuídos normalmente tendo como média a reta de regressão ajustada), ao passo que os resíduos do modelo de dados agregados são geralmente heterocedásticos (ibidem). Em meio às especificidades técnicas no ajuste de cada um dos modelos acima, é possível minimizar o problema da "falácia ecológica" lançando-se mão de modelos apropriados para a especificação dessas equações (Katz \& King 1999).

Por outro lado, quando se trata da especificação de modelos lineares não aditivos envolvendo variáveis que resultam da agregação de atributos individuais, há uma diferença crucial. Modelos não-aditivos são justamente os que contêm termos interativos (ou multiplicativos) que testam hipóteses condicionais, isto é, hipóteses que examinam se a direção e a magnitude da associação entre duas variáveis dependem linearmente do valor que assume uma terceira (ou mesmo uma das duas varáveis envolvidas na correlação). Uma ilustração de modelo não-aditivo para dados individuais aparece na equação abaixo ${ }^{6}$ :

$$
y_{i}=\beta_{0}+\beta_{1} x_{i 1} x_{i 2}+u_{i}
$$

Todavia, a equação que especifica esse mesmo padrão de associação nos dados agregados não é análoga à dos dados individuais. Novamente, aplicando-se o somatório aos dois lados da equação e dividindo-se pelo número de casos $n$, obtém-se o seguinte:

$$
\bar{y}_{g}=\beta_{0}+\beta_{1} \frac{\sum_{i=1}^{n}\left(x_{i 1} x_{i 2}\right)}{n}+\bar{u}_{g}
$$

O termo $\frac{\sum_{i=1}^{n}\left(x_{i 1} x_{i 2}\right)}{n}$ não se transforma automaticamente na simples multiplicação das médias das duas várias independentes. Nesse caso, ele corresponde à multiplicação das médias somada à covariância entre as duas variáveis. Sendo a covariância dada pela fórmula abaixo:

$$
s_{12 g}=\frac{\sum_{i=1}^{n}\left(x_{i 1} x_{i 2}\right)}{n}-\bar{x}_{g 1} \bar{x}_{g 2}
$$

A equação final para o modelo de regressão que utiliza as variáveis agregadas é $^{7}$ : 
${ }^{7}$ A prova de que $\frac{\sum_{i=1}^{n}\left(x_{i 1} x_{i 2}\right)}{n}$ é igual a $\bar{x}_{g 1} \bar{x}_{g 2}+s_{12 g}$ pode ser obtida simplesmente substituindo o termo $s_{12 g}$ pela fórmula dada acima.

\footnotetext{
${ }^{8}$ As consequências da omissão de uma variável independente para inferência são discutidas em King, Keohane e Verba (1994, p. 175). O grande problema desse tipo de erro de estimação é o possível viés nos coeficientes das demais variáveis independentes no modelo.
}

$$
\begin{aligned}
& \bar{y}_{g}=\beta_{0}+\beta_{1}\left(\bar{x}_{g 1} \bar{x}_{g 2}+s_{12 g}\right)+\bar{u}_{g} \\
& \bar{y}_{g}=\beta_{0}+\beta_{1} \bar{x}_{g 1} \bar{x}_{g 2}+\beta_{1} s_{12 g}+\bar{u}_{g}
\end{aligned}
$$

O que essa breve argumentação demonstra é que, na especificação de modelos não-aditivos para dados agregados, ocorre o clássico problema de viés por omissão de variável independente, uma vez que a covariância $s_{12 g}$ só pode ser obtida com os dados coletados no nível individual, e impede que o coeficiente $\beta_{1}$ sejaestimado corretamente (idem, p. 226) ${ }^{8}$. Portanto, o grande problema de tentar-se captar processos decisórios individuais por meio da análise de dados agregados ocorre mesmo quando se tem hipóteses condicionais. Vale mencionar que o viés discutido acima ocorre quando as médias de variáveis de nível individual são utilizadas (por exemplo, a média da escolaridade em um município) e, mais especificamente, quando a covariância $\left(s_{12 g}\right)$ entre duas variáveis no termo interativo é diferente de zero. Assim, o uso de variáveis agregadas que não são obtidas pela agregação de atributos individuais (como, por exemplo, se um sistema é parlamentarista ou presidencialista) não impugna o uso das interações, tendo em vista que a covariância entre tais indicadores dentro de cada agregado é igual a zero (já que são constantes em cada um deles).

Se os modelos lineares que buscam explicar a tomada de decisão individual para amostras inteiras pretendem superar supostas desvantagens da análise de dados agregados, eles não podem pretender abordar o problema da desigualdade entre os eleitores sem especificar as hipóteses condicionais que os modelos lineares de dados agregados não possibilitam. Nesse sentido, a análise da avaliação retrospectiva da economia enquanto um determinante do voto para presidente no Brasil ainda precisa testar com mais profundidade a hipótese da interação da sofisticação política.

As análises a seguir utilizam dados de pesquisa de opinião em painel. Pesquisas desse tipo consistem em entrevistas estruturadas realizadas ao longo do tempo com os mesmos indivíduos. A pesquisa utilizada aqui é intitulada The Dynamics of Political Attitude Formation in a Milieu of Multiple Weak Parties: A context-sensitive analysis of voting behavior in two brazilian cities (Baker, Ames \& Rennó 2006), e realizou ondas de entrevistas em abril-maio, agosto-setembro e outubro, em 2002, maio de 2004 e julho e outubro de 2006, nas cidades brasileiras de Juiz de Fora (MG) e Caxias do Sul (RS). Para gerar uma amostra de 2500 entrevistados em cada cidade na onda de abril-maio de 2002, utilizou-se o procedimento de múltiplos estágios com amostragem aleatória no nível da vizinhança, seguido do setor censitário, depois domicílio e, por fim, pessoas. Ao final da primeira onda, $74 \%$ do total das pessoas contatadas foram entrevistadas, e a mesma porcentagem foi obtida em setembro. Desses, $84 \%$ foram entrevistados na terceira onda de outubro de 2002 . No presente artigo são analisadas apenas as informações relativas às entrevistas feitas nas três ondas de 2002. Vale enfatizar que os dados analisados referem-se a Juiz de Fora e Caxias do Sul. Portanto, as hipóteses testadas nas análises a seguir apenas referem-se àquelas duas cidades. No entanto, mesmo que os dados não sejam representativos da totalidade do eleitorado brasileiro, e inviabilizem in- 
${ }^{9}$ Uma das obras mais importantes do campo de estudos de opinião pública foi baseada em uma pesquisa realizada na cidade de Elmira, EUA (Lazarsfeld, Berelson \& Gaudet 1965). No Brasil, os estudos realizados durante $\mathrm{o}$ regime militar também basearamse em cidades para estudar a dinâmica do processo eleitoral. Cidades como São Paulo (Lamounier 1975; 1980), Belo Horizonte (Reis 1975), e até mesmo Juiz de Fora (Reis 1978) e Caxias do Sul (Trindade \& De Cew 1978) estão entre as que foram analisadas.

${ }^{10}$ A lista de artigos mencionados certamente não esgota a produção que fez uso de tais modelos, sendo que apenas pretende fazer referência a alguns trabalhos representativos. Enquanto os dois primeiros artigos mencionados utilizaram o modelo binário com o estimador do tipo LOGIT, o último utilizou o estimador PROBIT. As diferenças entre os dois estimadores para modelos binários é muito pequena (Long 1997, p. 35). ferências de alcance mais amplo, há razões de natureza teórica para cogitar-se a plausibilidade das hipóteses no âmbito do eleitorado como um todo. Os elementos fundamentais que compõem a hipótese testada no artigo são a desigualdade da sofisticação política e as proposições de caráter nomológico corroboradas em outros contextos a respeito do impacto dessa variável sobre o processo de formação de preferências. A sugestão de que os mecanismos testados aqui não seriam plausíveis no contexto brasileiro mais geral presume que tais suposições sejam válidas devido tão somente a especificidades de Juiz de Fora e Caxias do Sul. Decerto, uma alegação desse tipo ignora o fato de que grande parte das teorias na área de opinião pública foram concebidas a partir de dados coletados em cidades específicas ${ }^{9}$.

A variável dependente nas análises seguintes é a intenção de voto para presidente na eleição de 2002, sendo quatro os candidatos principais na disputa: José Serra (candidato do PSDB, partido do então presidente Fernando Henrique Cardoso), Lula da Silva (PT), Anthony Garotinho (PSB) e Ciro Gomes (PPS). Assim, a variável caracteriza-se por ser nominal, isto é, composta por alternativas de análise não quantificáveis e entre as quais não há ordenamento numérico possível. Os estudiosos brasileiros têm utilizado dois tipos principais de modelos multivariados para analisar variáveis dependentes dessa natureza. O primeiro consiste em séries de modelos logísticos binários nos quais se analisa separadamente a preferência por cada candidato comparado ao conjunto dos demais (Carreirão \& Barbetta 2004; Carreirão 2007; Licio, Rennó e Castro 2009) ${ }^{10}$. A segunda opção consiste em utilizar o modelo logístico (ou LOGIT) multinomial, que visa a tratar diretamente de variáveis dependentes nominais com mais de duas categorias (Rennó 2006; Nicolau 2007; Peixoto \& Rennó 2011; Ribeiro, Carreirão \& Borba 2011). Nesse modelo, as probabilidades de voto nos candidatos são calculadas simultaneamente com relação a uma categoria de referência comum (um dos candidatos) definida pelo analista. Enquanto o uso da série de modelos binários pode resultar que, para um determinado eleitor, a soma das probabilidades de votar-se em cada candidato ultrapasse $100 \%$, os modelos multinomiais calculam as estatísticas de modo que a soma de tais probabilidades iguale $100 \%$.

No entanto, embora o modelo logístico multinomial torne-se cada vez mais popular nos estudos de comportamento eleitoral no Brasil, ele viola uma suposição crucial a respeito do comportamento do eleitor. Esse modelo toma como verdadeira a condição conhecida como "independência de alternativas irrelevantes" (IAI). O que essa condição denota é que a razão entre as probabilidades de um eleitor votar em dois candidatos hipotéticos não é afetada pela inclusão de um terceiro na disputa (Long 1997, p. 182; Alvarez \& Nagler 1998, p. 71). Como exemplo, cabe supor a situação em que um indivíduo tenha que escolher entre um carro ou um ônibus vermelho como meio de deslocamento. Inicialmente, esse indivíduo é indiferente em relação às duas opções, ou seja, sua probabilidade de escolher cada uma é igual a 50\%. Em um segundo momento, a empresa que oferece o serviço do ônibus vermelho passa a oferecer adicionalmente um ônibus da cor azul. A IAI refere-se ao fato de que, nesse momento, as probabilidades iniciais se ajustarão para aproximadamente $33 \%$ (um terço para carro, outro para ônibus vermelho e outro para o ônibus azul). Isso implica que a inclusão do ônibus azul no conjunto de alternativas disponíveis afeta igualmente às probabilidades de o indivíduo escolher o carro e o ônibus vermelho. No entanto, se a única característica que distingue os dois ônibus é a cor, não é razoável supor que indivíduos que prefiram o carro no cenário inicial passem a preferir o ônibus no segundo momento. Isso implica- 
${ }^{11}$ Alvarez e Nagler (1998) chegam a considerar que, por essa razão, o uso de séries de modelos binários seria menos problemático do que o uso do modelo logístico multinomial.

${ }^{12}$ Vale mencionar que, apesar de o modelo multinomial PROBIT solucionar o problema da violação da IAI, ele também apresenta limitações. Uma delas é de que é extremamente sensível à distribuição dos dados e pode apresentar problemas de identificação, especialmente conforme se reduz o tamanho a amostra utilizada (Dow \& Endersby 2004).

${ }^{13}$ Nos procedimentos de preparação das variáveis e na análise das correlações inter-temporais entre as avaliações da economia foi utilizada a versão 2.13 .1 do $R$. Nos modelos de análise estatística multivariada (PROBIT multinomial) foi utilizada a versão 11.1 do STATA.

${ }^{14} \mathrm{O}$ fraseado da pergunta sobre avaliação sociotrópica era o seguinte: "Falando em geral do país nos últimos 12 meses, você acha que a situação econômica melhorou muito, melhorou pouco, ficou igual, piorou pouco ou piorou muito?"

${ }^{15} \mathrm{O}$ fraseado da pergunta sobre avaliação pessoal era o seguinte: "Com relação à sua situação econômica pessoal, nos últimos 12 meses você acha que ela melhorou muito, melhorou pouco, ficou igual, piorou pouco ou piorou muito?"

${ }^{16}$ Duch e Stevenson (2008) obtiveram o mesmo resultado em suas análises em 18 países em um intervalo de mais de 20 anos. ria que a probabilidade de escolher-se o carro seria reduzida sempre que outra cor de ônibus tornasse-se disponível (Long 1997, p. 183). Ou seja, tal situação supõe uma condição patentemente irrealista sobre o comportamento de escolha dos indivíduos. O modelo logístico multinomial apresenta essa limitação uma vez que restringe a estimação as probabilidades de escolher-se cada alternativa sem referência às características das demais. Sendo assim, Alvarez e Nagler (1998, pp. 72-73) argumentam que tais modelos seriam problemáticos para o estudo do voto em sistemas multipartidários, especialmente para os estudos do voto retrospectivo, já que a adição de um candidato de oposição tenderia a afetar mais as probabilidades de voto nos demais candidatos oposicionistas do que no candidato da situação ${ }^{11}$. Uma alternativa viável para contornar-se o problema da violação da IAI é o modelo multinomial que usa o estimador do tipo PROBIT, uma vez que este leva em conta todo o conjunto de alternativas sem assumir a condição de IAI (idem) ${ }^{12}$. As análises do voto feitas a seguir utilizam esse tipo de modelo ${ }^{13}$.

O artigo tem como principais variáveis independentes os dois tipos de avaliação retrospectiva da economia comumente utilizados na literatura: a avaliação sociotrópica e a avaliação da situação econômica do próprio respondente (avaliação pessoal). A primeira busca captar a opinião do respondente a respeito da economia do país nos 12 meses anteriores à aplicação do questionário ${ }^{14}$. A segunda consiste na opinião do respondente sobre sua própria situação econômica nos últimos 12 meses $^{15}$. Como os modelos apresentados no artigo incluem termos multiplicativos entre as variáveis de avaliação da economia e a variável de sofisticação política, optou-se por tratar as primeiras como contínuas em vez de incluir-se variáveis indicadoras de cada categoria de resposta. Modelos especificados paralelamente aos que são apresentados abaixo mostraram que esse tratamento não modifica os resultados finais, sendo mais simples a apresentação dos modelos da maneira como se seguem ${ }^{16}$.

Outra variável teoricamente relevante utilizada é a da sofisticação política, que se refere à quantidade de informações políticas um indivíduo possui e sua capacidade de integrá-las (Luskin 1990, p. 332; Neuman 1981, p. 1 237). A capacidade de identificar e discriminar os diversos assuntos, pessoas e fatos da política refere-se à dimensão da diferenciação conceitual, enquanto a organização das ideias e assuntos políticos em construtos mais abstratos seria uma segunda dimensão, a integração conceitual (Fuks \& Batista Pereira 2011, pp. 126-127; Luskin 1987, p. 861; Neuman 1981, p. 1 237). Segundo Luskin (1987), as medidas de diferenciação consistiriam em perguntas mais diretas (fechadas ou abertas) de informações factuais sobre política. Já as medidas de integração conceitual geralmente se baseariam na avaliação da capacidade dos respondentes de associar corretamente pessoas e partidos aos "lados" da política, ou na construção de escores a partir da codificação das respostas dadas a questões abertas nas quais o respondente demonstraria a capacidade de reconhecer e entender conceitos mais abstratos da política.

Há duas principais dificuldades na mensuração do construto de sofisticação política tal como discutido acima. Em primeiro lugar, questões abertas sobre capacidade de conceituação seriam demasiado custosas pelo fato de serem longas e demandarem complexos procedimentos de pós-codificação. Em segundo lugar, as baterias de perguntas sobre diferenciação (quantidade de cognições) dificilmente captariam toda a gama de informações políticas disponíveis nos ambientes nos quais se encontram os cidadãos. No entanto, ainda que tais críticas sejam pertinentes, a produção acadêmica sobre a mensuração da sofisticação tratou de propor soluções parcimoniosas e válidas para o construto. No 
${ }^{17}$ Delli Carpini e Keeter (1996) também encontram diversas subdimensões da sofisticação política nas dezenas de perguntas de conhecimento que analisaram. As distinções encontradas entre dimensões se refeririam aos assuntos tratados em cada pergunta. Por exemplo, questões sobre política nacional formariam uma sub-dimensão, enquanto as de política internacional formariam outra. De todo modo, as duas sub-dimensões seriam altamente correlacionadas.

\footnotetext{
${ }^{18}$ Foi utilizado o modelo logístico de dois parâmetros (dificuldade e discriminação) com estimação por máxima verossimilhança para análise dos itens e construção da escala.

${ }^{19}$ Apenas as variáveis indicadoras da identificação com PT e PSDB foram incluídas nos modelos, haja vista que as proporções de respondentes identificados com os partidos dos demais candidatos a presidente foram minúsculas.

${ }^{20}$ A questão oferecia cinco categorias de resposta aos respondentes (muito esquerda, esquerda, centro, direita e muito direita). Nas análises a seguir, as opções "esquerda" e "muito esquerda" foram codificadas como apenas esquerda, e o mesmo foi feito com as categorias à direita. A opção centro foi incluída nos modelos como uma variável indicadora, sendo que a categoria e referência foi a não resposta.
}

que se refere ao primeiro problema, os trabalhos de Neuman (1981) e Luskin (1987) desenvolvem estratégias para mensurar as duas dimensões da sofisticação e concluíram que, ainda que conceitualmente separáveis, as duas seriam altamente correlacionadas. O trabalho recente de Fuks e Batista Pereira (2011) com dados brasileiros também encontra os mesmos resultados. Portanto, esses trabalhos mostram que as medidas mais simples de posse de informações factuais seriam aproximações adequadas do construto latente mais amplo da sofisticação política. Já no que se refere ao problema da capacidade de tais baterias cobrirem todo o conteúdo possível do universo simbólico da política, o trabalho de Delli Carpini e Keeter (1996) fornece uma resposta. Trata-se aqui do clássico problema de mensuração relacionado à validade de conteúdo das medidas. Os autores incluem em uma mesma pesquisa dezenas de perguntas de conhecimento sobre política e verificam que tais indicadores seriam altamente correlacionados entre si, e poderiam ser utilizados para representar uma única dimensão conceitual ${ }^{17}$. Nesse sentido, não é necessário utilizar um número muito elevado de perguntas sobre política para captar-se a variação individual no que se refere ao atributo mensurado. Se não há como atingir uma representação perfeita de tudo que os indivíduos sabem ou podem saber sobre política, é possível ao menos representar de forma relativamente adequada a desigualdade do atributo da sofisticação política entre os indivíduos.

Com base nas considerações acima, a medida de sofisticação política do artigo baseia-se em uma bateria de perguntas de informações factuais que foi aplicada na onda de abril da pesquisa. Ao final da aplicação do questionário foram perguntadas seis questões de múltipla escolha sobre informações políticas. Os respondentes foram perguntados quem era o vice-presidente do Brasil na época, qual o partido do então presidente Fernando Henrique Cardoso, qual país em uma lista faria parte do Mercosul, e também o nome do presidente da Câmara dos Deputados. Outras duas perguntas eram específicas de cada cidade, mas eram análogas entre si. Uma pedia que o respondente identificasse, entre as quatro alternativas, aquela que continha o nome de um senador de seu estado. Outra pergunta mencionava o nome de um político (um deputado federal da cidade) e pedia que o respondente identificasse seu cargo. As demais alternativas nas duas perguntas eram iguais para Caxias do Sul e Juiz de Fora. A medida final de sofisticação política utilizada nas análises que se seguem foi construída a partir da Teoria de Resposta ao Item - TRI (Baker 2001; Birnbaum 1968). Em linhas gerais, essa teoria entende que o desempenho de um indivíduo em uma questão depende da dificuldade do teste e da habilidade latente do indivíduo. Com as questões tendo pesos diferentes no construto (por conta de níveis diferentes de dificuldade e discriminação), obtém-se mais pontos na escala e, consequentemente, maior variabilidade entre os indivíduos no atributo mensurado. $\mathrm{O}$ construto final obtido por TRI foi re-escalado de modo que o valores mínimo e máximo fossem 0 e 6 . Isso fez que a escala por TRI tivesse múltiplos valores entre 0 a 6 e adquirisse uma interpretação mais próxima da simples escala aditiva ${ }^{18}$.

As demais variáveis nos modelos são a preferência partidária ${ }^{19}$, a auto-localização ideológica ${ }^{20}$, a escolaridade e a idade (medidas em anos completos), o sexo e a raça (variáveis binárias tendo como categorias de referência as mulheres e os que declaram não serem brancos, respectivamente). $\mathrm{O}$ artigo utiliza os modelos multinomiais PROBIT para testar a hipótese de que o voto econômico, isto é, a associação entre avaliação da economia e voto, depende do nível de sofisticação política do eleitor. Também serão apresentadas algumas correlações entre as avaliações da economia ao longo do tempo para diferentes 
níveis de sofisticação política a fim de saber-se quais indivíduos possuem opiniões mais estáveis sobre a economia ${ }^{21}$.

\section{Economia, sofisticação política e voto na eleição presidencial de 2002}

${ }^{21}$ As estatísticas descritivas e as correlações bivariadas entre as variáveis utilizadas nas análises a seguir podem ser requisitadas junto ao autor por correio eletrônico.

\footnotetext{
${ }^{22}$ Esse tipo de correlação parte da concepção forte a respeito da correlação, isto é, a concepção de monotonicidade perfeita (Weisberg 1974), segundo a qual o valor da estatística de correlação aumenta (aproximando-se de 1) na medida em que aumenta a proporção de casos nos pares concordantes na tabela de contingência entre as variáveis. Na medida em que a proporção de casos discordantes aumenta, a correlação diminui (aproximando-se de -1). Valores próximos de 0 que indicam ausência de correlação.

${ }^{23}$ Todas as associações apresentadas são estatisticamente significativas a 0,01 .
}

Esta seção utiliza a análise multivariada de dados para examinar em que medida a sofisticação política condiciona o efeito da avaliação econômica sobre o voto para presidente em 2002. Para as análises abaixo, foram selecionados os respondentes da pesquisa de Juiz de Fora e Caxias do Sul que apareceram nas entrevistas aplicadas nas três ondas da pesquisa (abril-maio, setembro e outubro).

O primeiro passo das análises é examinar a estabilidade da avaliação retrospectiva da economia e sua relação com a sofisticação política dos respondentes. A Tabela 1 apresenta as correlações tau-B de Kendall entre os itens ordinais de avaliação retrospectiva sociotrópica e pessoal ao longo do tempo ${ }^{22}$ :

Os resultados da Tabela 1 mostram que, em média, as associações entre as avaliações da economia ao longo do tempo são baixas ou moderadas e apenas passam de 0,5 em uma das células dos respondentes do quartil mais sofistica$\mathrm{do}^{23}$. Isso significa que, em geral, menos da metade dos respondentes fornece exatamente a mesma resposta à pergunta sobre a avaliação retrospectiva nos dois pontos do tempo. Uma observação possível aqui é a de que a economia o objeto sendo avaliado - talvez tenha apresentado flutuações frequentes no período em questão, levando os respondentes a darem respostas instáveis, o que não pode ser testado com os dados de que se dispõe aqui. Em segundo lugar, a correlação entre as avaliações retrospectivas sociotrópica e pessoal no tempo tende a aumentar conforme se passa do primeiro para o último quartil, isto é, quando se aumenta o nível de sofisticação política do subgrupo de respondentes. No entanto, esse efeito da sofisticação política é fraco. Além disso, pode-se conjecturar que a economia (tanto no nível pessoal quanto do país) tenha apresentado oscilações durante o período em questão justamente entre os respondentes menos sofisticados, o que causaria a instabilidade de suas opiniões. Não é possível testar essa hipótese com os dados analisados aqui e, portanto, não se pode descartar a possibilidade que ela aventa.

Seja como for, o passo mais importante no exame da hipótese da interação da sofisticação política sobre o efeito da avaliação retrospectiva da economia refere-se à efetividade com que ela afeta a escolha do candidato. Conforme argumentou-se anteriormente, $\mathrm{o}$ ato de conectar a opinião sobre o desempenho

Tabela 1 - Correlações tau-B de Kendall entre avaliações da economia

\begin{tabular}{cccccc}
\hline & $\begin{array}{c}\text { Quartil 1 } \\
\mathrm{n}=740\end{array}$ & $\begin{array}{c}\text { Quartil 2 } \\
\mathrm{n}=690\end{array}$ & $\begin{array}{c}\text { Quartil 3 } \\
\mathrm{n}=872\end{array}$ & $\begin{array}{c}\text { Quartil 4 } \\
\mathrm{n}=733\end{array}$ & $\begin{array}{c}\text { Amostra total } \\
\mathrm{n}=3035\end{array}$ \\
\hline $\begin{array}{c}\text { Avaliação pessoal } \\
\text { abril-setembro }\end{array}$ & 0,35 & 0,36 & 0,38 & 0,45 & 0,38 \\
setembro-outubro & 0,39 & 0,49 & 0,46 & 0,53 & 0,47 \\
$\quad \begin{array}{c}\text { abril-outubro } \\
\text { Avaliação sociotrópica }\end{array}$ & 0,29 & 0,32 & 0,35 & 0,41 & 0,34 \\
abril-setembro & 0,24 & 0,20 & 0,25 & 0,33 & 0,26 \\
setembro-outubro & 0,26 & 0,27 & 0,26 & 0,36 & 0,29 \\
abril-outubro & 0,20 & 0,21 & 0,21 & 0,29 & 0,23 \\
\hline
\end{tabular}

Fonte: $\mathrm{O}$ autor. 
${ }^{24}$ Como se trata de três modelos multinomiais com quatro alternativas de resposta em cada, obtémse nove estimativas diferentes do efeito de cada variável independente sobre o voto. Para facilitar a apresentação e a interpretação dos resultados, optou-se por apresentar, na Tabela 2, apenas os coeficientes de interesse mais direto para as hipóteses testadas. Os efeitos das demais variáveis se encontram nas tabelas do apêndice.

${ }^{25}$ A renda não apresentou efeito substantivo em modelos paralelos. Como muitos respondentes tendem a omitir essa informação, fazendo com que a variável tenha uma proporção muito maior de casos sem resposta do que as demais, optou-se por excluí-la dos modelos finais apresentados aqui. da economia do país ou da própria situação pessoal com o voto para presidente não é tão simples quanto parece. A emissão de uma opinião sobre o desempenho da economia ao longo do último ano requer que o indivíduo tenha em conta uma série de considerações a respeito do assunto, e isso denota justamente que a avaliação retrospectiva é um determinante do voto cujo efeito dependeria diretamente de certa quantidade mínima de informações que o eleitor possui.

Para testar-se as proposições defendidas acima, foram utilizados modelos multinomiais do tipo PROBIT para explicar o voto em cada candidato nas três ondas da pesquisa, conforme discutiu-se na seção anterior. No modelo também é importante controlar o efeito da avaliação retrospectiva pelos de outras preferências e atitudes políticas dos respondentes, a fim de se isolar a variação na variável dependente (a probabilidade de se votar em cada candidato) que se deve exclusivamente às avaliações da economia. $\mathrm{O}$ teste principal nos modelos apresentados a seguir consiste na inserção de termos interativos (ou multiplicativos) entre a variável da sofisticação política e as duas avaliações retrospectivas da economia (sociotrópica e pessoal). Como as escalas de avaliação variam de um pólo positivo a um pólo negativo, espera-se que elas tenham efeitos positivos sobre os votos em Lula, Garotinho e Ciro Gomes, candidatos de oposição naquele pleito, e efeitos negativos sobre o voto em Serra, candidato da situação. Os termos interativos testam justamente se a sofisticação potencializa ou não os efeitos das avaliações retrospectivas sobre o voto. Caso esses termos multiplicativos tenham efeitos fortes e no sentido esperado, será possível inferir que os mais sofisticados são os que com mais frequência baseiam-se em avaliações da economia para escolherem o candidato a presidente. Também é crucial que se examine os efeitos isolados das variáveis de avaliação retrospectiva. Caso sejam altos e no sentido esperado, poder-se-á dizer que os eleitores menos sofisticados conectam suas avaliações da economia com o voto para presidente, independentemente de se os eleitores mais sofisticados sejam mais ou menos eficientes em fazê-lo (ou seja, independentemente do termo interativo). Além dessas variáveis principais e das variáveis que controlam por outras preferências e atitudes políticas dos respondentes (preferência partidária e auto-localização ideológica), também foram inseridos controles por variáveis relativas ao perfil socioeconômico dos respondentes ${ }^{24}$. Isso tornou os modelos ajustados mais parecidos com os das análises brasileiras que não incorporam a interação com a sofisticação política ${ }^{25}$.

Os coeficientes apresentados na Tabela 2 são de difícil interpretação da maneira como aparecem ${ }^{26}$. Mesmo assim, um exame mais superficial de sua direção e magnitude permite observar que a avaliação retrospectiva da situação pessoal do respondente não apresenta padrões claros de associação com o voto nos candidatos em todos os modelos. Tampouco os termos interativos entre avaliação pessoal e sofisticação política apresentam tendências claras. Portanto, não se verifica o chamado voto econômico quando se trata do efeito que a avaliação que o respondente faz da própria situação econômica tem sobre seu voto. Por outro lado, em quatro dos nove modelos é possível encontrar as tendências que se esperava em relação ao efeito da avaliação retrospectiva sociotrópica $^{27}$. No entanto, os coeficientes omitem José Serra, que é a categoria de referência, inviabilizando assim a visualização do impacto das variáveis sobre a probabilidade de votar-se nesse candidato. Para melhorar a leitura dos resultados, os gráficos abaixo apresentam o que se chama de simulação dos valores de interesse dos modelos ajustados. Eles revelam a magnitude do efeito da avaliação retrospectiva sociotrópica da economia sobre o voto para três dife- 
O procedimento não altera os resultados encontrados.

${ }^{26}$ A interpretação do valor do coeficiente do tipo PROBIT não corresponde ao aumento ou diminuição da probabilidade de votarse no candidato, diferentemente do que ocorre no modelo linear simples. Além disso, o efeito do aumento de uma unidade na variável independente depende dos valores das demais variáveis dependentes no modelo, bem como do valor inicial da variável independente em questão.

${ }^{27}$ Esse é o caso se a significância estatística for tomada como único critério de relevância dos efeitos. Por outro lado, o exame das magnitudes mostra que o efeito interativo da sofisticação política afeta a escolha dos candidatos em todos os modelos, como se verá mais a frente.

\footnotetext{
${ }^{28} \mathrm{O}$ efeito da avaliação retrospectiva pessoal da economia não é ilustrado nos gráficos porque não foi relevante nos modelos testados acima.

${ }^{29}$ O programa de computador calcula os valores preditos para 100 amostras simuladas a partir dos resultados do modelo, e utiliza a distribuição desses valores preditos simulados para gerar
}

Tabela 2 - Modelo PROBIT Multinomial - Impacto das avaliações econômicas sobre o voto para toda a amostra

\begin{tabular}{|c|c|c|c|}
\hline Variável independente & $\begin{array}{c}\text { Coeficiente } \\
\text { (Erro Padrão) }\end{array}$ & $\begin{array}{c}\text { Coeficiente } \\
\text { (Erro Padrão) }\end{array}$ & $\begin{array}{c}\text { Coeficiente } \\
\text { (Erro Padrão) }\end{array}$ \\
\hline & \multicolumn{2}{|c|}{ Abril/Maio } & \\
\hline & Lula & Garotinho & Ciro \\
\hline \multirow[t]{2}{*}{ Av. Sociotrópica } & $-0,05$ & 0,03 & 0,03 \\
\hline & $(0,09)$ & $(0,09)$ & $(0,11)$ \\
\hline \multirow[t]{2}{*}{ Av. Pessoal } & $-0,03$ & $-0,14$ & $-0,09$ \\
\hline & $(0,11)$ & $(0,11)$ & $(0,12)$ \\
\hline \multirow[t]{2}{*}{ Sofisticação } & $-0,36 * * *$ & $-0,35 * * *$ & $-0,18^{*}$ \\
\hline & $(0,09)$ & $(0,09)$ & $(0,10)$ \\
\hline \multirow[t]{2}{*}{ Av. Sociotrópica*Sofisticação } & $0,07 * * *$ & 0,03 & 0,04 \\
\hline & $(0,02)$ & $(0,03)$ & $(0,03)$ \\
\hline \multirow[t]{4}{*}{ Av. Pessoal*Sofisticação } & 0,02 & 0,05 & 0,01 \\
\hline & $(0,03)$ & $(0,03)$ & $(0,03)$ \\
\hline & Set & mbro & \\
\hline & Lula & Garotinho & Ciro \\
\hline \multirow[t]{2}{*}{ Av. Sociotroópica } & 0,03 & 0,08 & $-0,02$ \\
\hline & $(0,08)$ & $(0,09)$ & $(0,09)$ \\
\hline \multirow[t]{2}{*}{ Av. Pessoal } & 0,08 & $-0,01$ & 0,01 \\
\hline & $(0,09)$ & $(0,10)$ & $(0,09)$ \\
\hline \multirow[t]{2}{*}{ Sofisticação } & $-0,22 * * *$ & $-0,22 * * *$ & $-0,03$ \\
\hline & $(0,08)$ & $(0,10)$ & $(0,08)$ \\
\hline \multirow[t]{2}{*}{ Av. Sociotrópica*Sofisticação } & $0,06^{* * *}$ & 0,02 & 0,03 \\
\hline & $(0,02)$ & $(0,03)$ & $(0,02)$ \\
\hline \multirow[t]{4}{*}{ Av. Pessoal*Sofisticação } & 0,00 & 0,01 & $-0,01$ \\
\hline & $(0,03)$ & $(0,03)$ & $(0,03)$ \\
\hline & $\mathrm{Ou}$ & ubro & \\
\hline & Lula & Garotinho & Ciro \\
\hline \multirow[t]{2}{*}{ Av. Sociotroópica } & 0,07 & 0,03 & 0,01 \\
\hline & $(0,09)$ & $(0,10)$ & $(0,12)$ \\
\hline \multirow[t]{2}{*}{ Av. Pessoal } & 0,03 & 0,11 & 0,13 \\
\hline & $(0,10)$ & $(0,11)$ & $(0,13)$ \\
\hline \multirow[t]{2}{*}{ Sofisticação } & $-0,22 * * *$ & $-0,22 * * *$ & $-0,04$ \\
\hline & $(0,08)$ & $(0,09)$ & $(0,09)$ \\
\hline \multirow[t]{2}{*}{ Av. Sociotrópica*Sofisticação } & 0,03 & $0,06 * * *$ & $0,06^{*}$ \\
\hline & $(0,03)$ & $(0,03)$ & $(0,03)$ \\
\hline \multirow[t]{2}{*}{ Av. Pessoal*Sofisticação } & 0,02 & $-0,03$ & $-0,03$ \\
\hline & $(0,03)$ & $(0,03)$ & $(0,03)$ \\
\hline
\end{tabular}

*** Estatisticamente significativo a 0,01

** Estatisticamente significativo a 0,05

* Estatisticamente significativo a 0,10

Fonte: $\mathrm{O}$ autor.

rentes níveis de sofisticação política ${ }^{28}$. Foi utilizada a técnica de bootstrapping para simular os efeitos em amostras hipotéticas e gerar as probabilidades ${ }^{29}$.

Para efeito de comparação, apresentaremos a seguir 12 curvas, três para cada um dos quatro candidatos. As Figuras 1 a 4 trazem os resultados para a avaliação sobre a probabilidade de voto em abril. A seguir, as Figuras 5 a 8 contém os resultados para o mês de setembro. Finalmente, veremos como a magnitude do efeito da avaliação se comporta no mês de outubro (para os quatro candidatos). Isso aparece nas Figuras 9 a 12. 
Figura 1 - Efeito da avaliação retrospectiva sociotrópica sobre a probabilidade de voto em cada candidato de acordo com o nível de sofisticação política, abril (Serra)

1. Serra

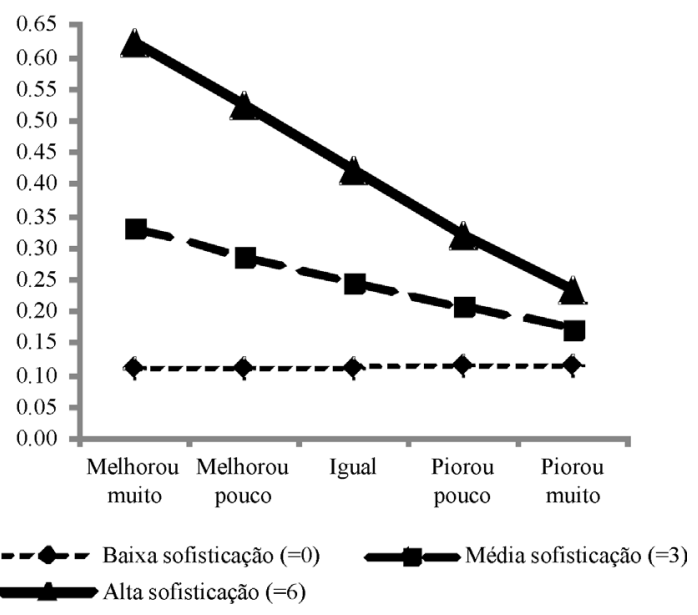

Fonte: $\mathrm{O}$ autor.
Figura 2 - Efeito da avaliação retrospectiva sociotrópica sobre a probabilidade de voto em cada candidato de acordo com o nível de sofisticação política, abril (Lula)

\section{Lula}

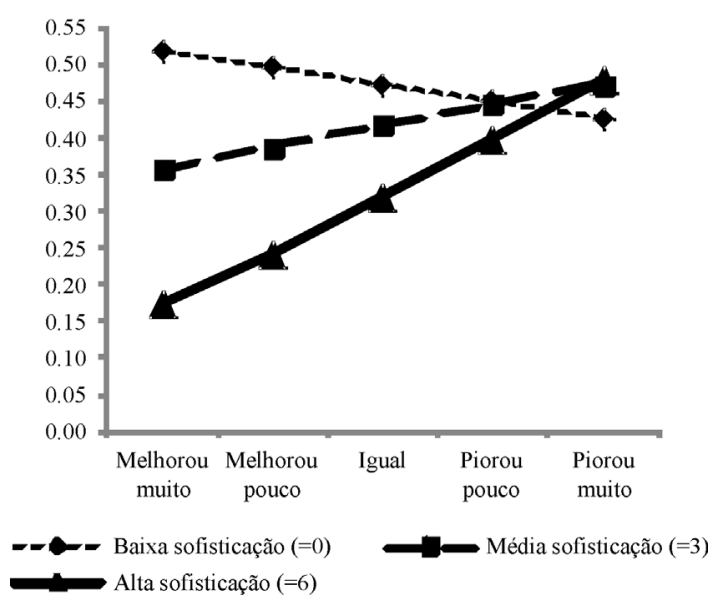

Fonte: $\mathrm{O}$ autor.

Os gráficos do efeito da avaliação retrospectiva sociotrópica sobre o voto em Serra (Figuras 1, 5 e 9) são os que revelam de forma mais clara a diferença entre os eleitores mais e menos politicamente sofisticados. $\mathrm{O}$ que se nota é que a inclinação da reta é bem mais acentuada entre os eleitores mais sofisticados nas três ondas da pesquisa, ao passo que, para o subgrupo menos sofisticado, a avaliação da economia do país não parece afetar a probabilidade de que o respondente vote em José Serra. No que se refere ao voto em Lula, nota-se que sua associação mais geral com a avaliação retrospectiva sociotrópica diminui com o tempo. Em abril e setembro é possível notar o efeito interativo substancial da sofisticação. Em abril (Figura 2), enquanto a má avaliação da economia claramente aumenta a probabilidade do respondente mais sofisticado votar em

Figura 3 - Efeito da avaliação retrospectiva sociotrópica sobre a probabilidade de voto em cada candidato de acordo com o nível de sofisticação política, abril (Garotinho)

\section{Garotinho}

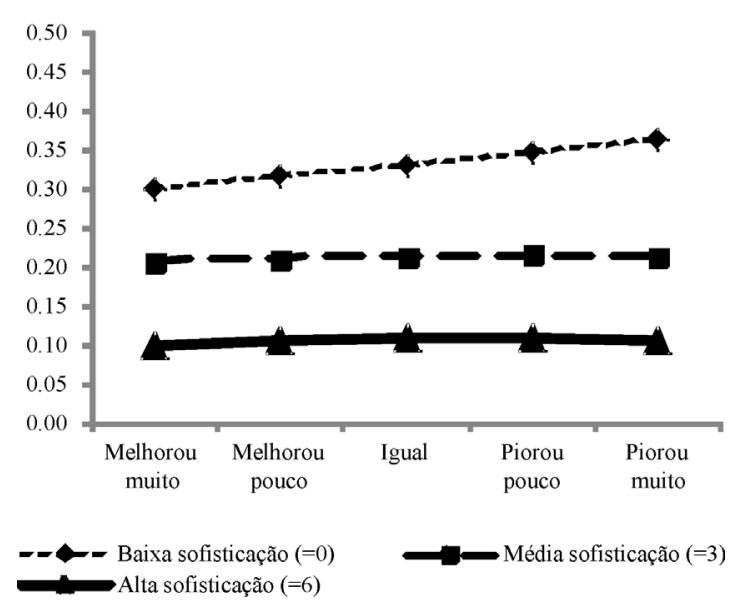

Fonte: $\mathrm{O}$ autor.
Figura 4 - Efeito da avaliação retrospectiva sociotrópica sobre a probabilidade de voto em cada candidato de acordo com o nível de sofisticação política, abril (Ciro)

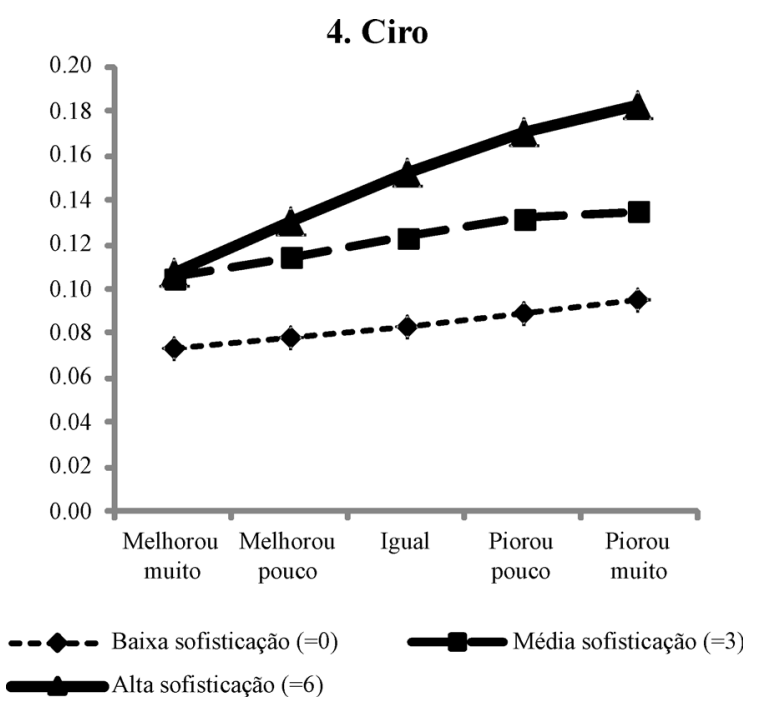

Fonte: $\mathrm{O}$ autor. 
Figura 5 - Efeito da avaliação retrospectiva sociotrópica sobre a probabilidade de voto em cada candidato de acordo com o nível de sofisticação política, setembro (Serra)

\section{Serra}

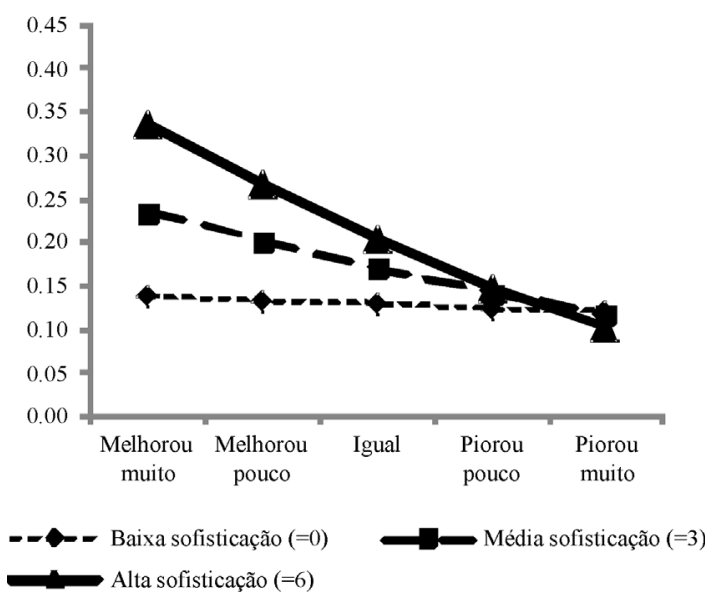

Fonte: $\mathrm{O}$ autor.
Figura 6 - Efeito da avaliação retrospectiva sociotrópica sobre a probabilidade de voto em cada candidato de acordo com o nível de sofisticação política, setembro (Lula)

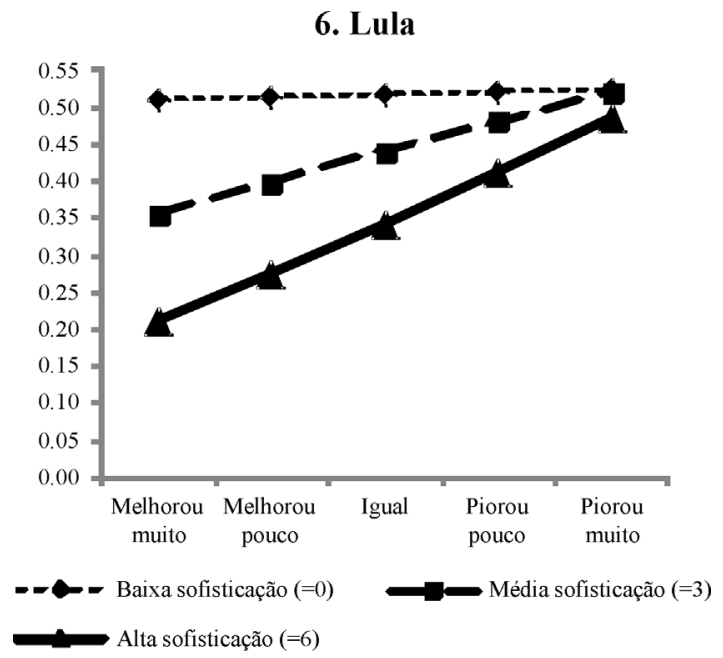

Fonte: $\mathrm{O}$ autor.

Lula, ela tem o efeito contrário ao esperado entre os eleitores menos sofisticados. Ou seja, avaliar mal a economia diminui a probabilidade de um eleitor de baixa sofisticação votar em Lula, principal candidato da oposição. Já em setembro (Figura 6) o efeito passa a ser positivo para todos os eleitores, mas é visível que a inclinação da curva é mais acentuada entre os mais politicamente sofisticados, indicando que são esses os eleitores que conectam efetivamente a avaliação da economia com o voto no candidato. No entanto, essa diferença desaparece completamente em outubro (Figura 10).

Figura 7 - Efeito da avaliação retrospectiva sociotrópica sobre a probabilidade de voto em cada candidato de acordo com o nível de sofisticação política, setembro (Garotinho)

\section{Garotinho}

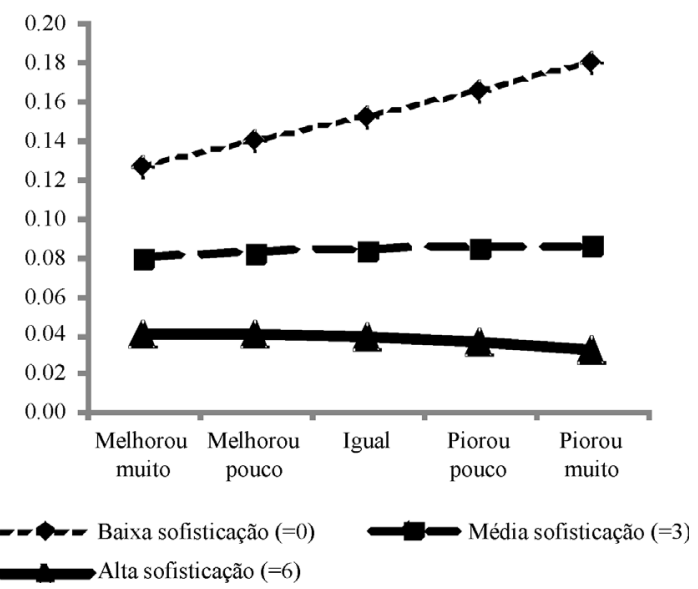

Fonte: $\mathrm{O}$ autor.
Figura 8 - Efeito da avaliação retrospectiva sociotrópica sobre a probabilidade de voto em cada candidato de acordo com o nível de sofisticação política, setembro (Ciro)

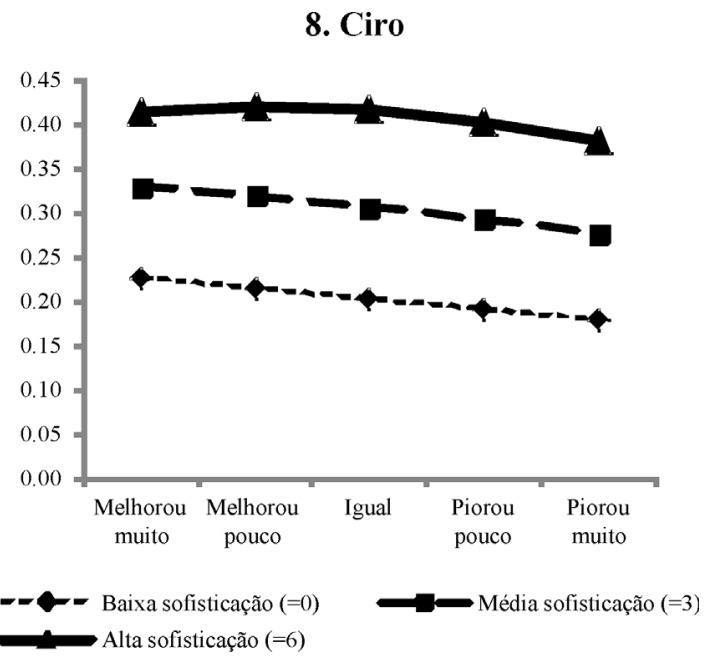

Fonte: O autor. 
Figura 9 - Efeito da avaliação retrospectiva sociotrópica sobre a probabilidade de voto em cada candidato de acordo com o nível de sofisticação política, outubro (Serra)

\section{Serra}

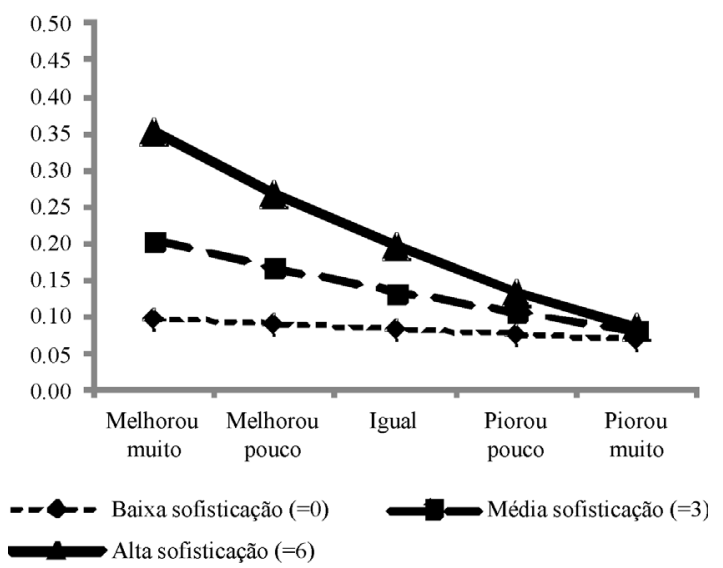

Fonte: $\mathrm{O}$ autor.
Figura 10 - Efeito da avaliação retrospectiva sociotrópica sobre a probabilidade de voto em cada candidato de acordo com o nível de sofisticação política, outubro (Lula)

\section{Lula}

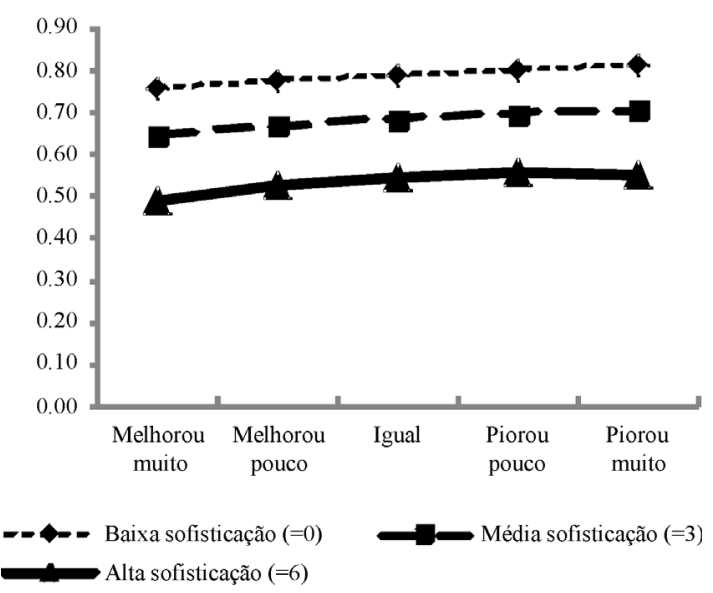

Fonte: $\mathrm{O}$ autor.

Outro aspecto a ser assinalado sobre os resultados de Serra e Lula tem a ver com o impacto da sofisticação sobre as proporções de votos de cada candidato. No caso de Serra, é visível que, caso o nível de sofisticação política do grupo menos sofisticado fosse aumentado até o dos mais sofisticados, o candidato ganharia votos. Essa constatação é possível caso se observe o grupo de respondentes que declara que a economia "melhorou muito". Nas Figuras 1, 5 e 9 percebe-se que, caso os menos sofisticados "ganhassem" sofisticação, sua probabilidade de votar em Serra aumentaria 55, 20 e 35 pontos percentuais, respectivamente. O mesmo não ocorre no outro extremo da distribuição, para os respondentes segundo os quais a economia "piorou muito". Nesse caso, caso se elevasse o nível de sofisticação dos menos sofisticados, sua probabilidade de

Figura 11 - Efeito da avaliação retrospectiva sociotrópica sobre a probabilidade de voto em cada candidato de acordo com o nível de sofisticação política, outubro (Garotinho)

\section{Garotinho}

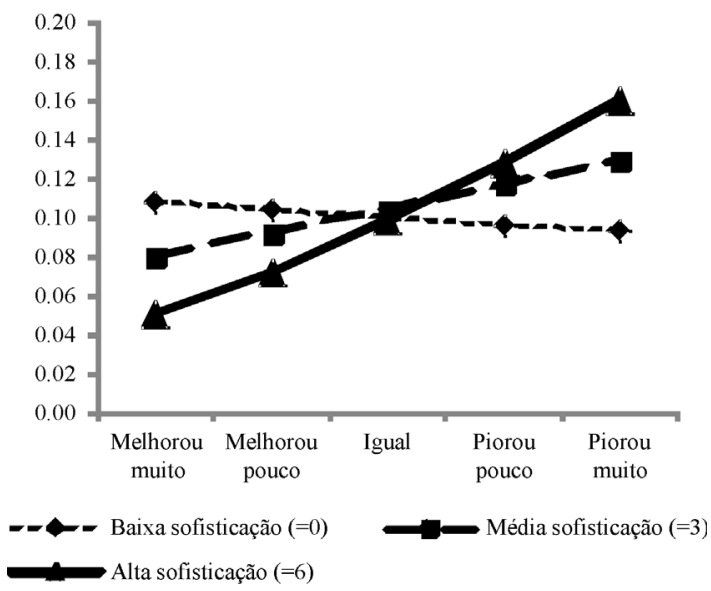

Fonte: $\mathrm{O}$ autor.
Figura 12 - Efeito da avaliação retrospectiva sociotrópica sobre a probabilidade de voto em cada candidato de acordo com o nível de sofisticação política, outubro (Ciro)

\section{Ciro}

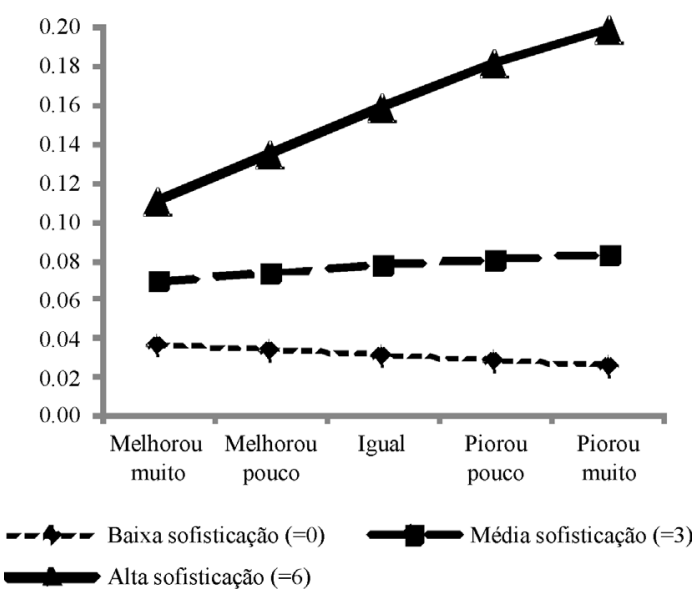

Fonte: O autor. 
votar contra Serra não seria significativamente alterada. Lula, por outro lado, parece beneficiar-se do efeito da sofisticação em abril e setembro (Figuras $2 \mathrm{e}$ 6), mas não em outubro (Figura 10). Caso se aumentasse o nível de sofisticação dos eleitores que consideram que a economia "melhorou muito", a probabilidade desses indivíduos votarem em Lula diminuiria em cerca de $40 \%$ e $35 \%$ em abril e setembro, respectivamente. Do ponto de vista teórico, o que se acena é a possibilidade de que a distribuição dos votos poderia ser diferente caso o eleitorado fosse mais politicamente sofisticado (Bartels 1986). Obviamente, a evidência refere-se apenas ao efeito da avaliação da economia sobre o voto, ignorando outros determinantes. A evidência também se restringe às probabilidades hipotéticas geradas a partir dos modelos estatísticos. Além disso, não se pode saber se, caso os menos sofisticados "ganhassem" sofisticação, suas avaliações da economia seriam as mesmas, tal como a análise acima pressupõe.

No caso da escolha de Garotinho, apenas em outubro (Figura 11) verificase claramente o efeito condicional da sofisticação política sobre o voto econômico retrospectivo. Em abril e setembro (Figuras 3 e 7) observa-se na verdade um efeito negativo da sofisticação política, indicando que os eleitores menos sofisticados seriam os mais propensos a basear-se em considerações econômicas para escolher o candidato. No entanto, tal efeito é fraco e não apresenta significância estatística em nenhum dos casos. Para a escolha de Ciro Gomes, apenas em setembro (Figura 8) o efeito condicional da sofisticação política não se verifica. Em abril e outubro (Figuras 4 e 12) os mais politicamente sofisticados são visivelmente mais propensos a basearem-se na avaliação da economia para votar em Ciro do que os menos sofisticados.

Em suma, os resultados mostram que pode ser mesmo inadequado assumir que a avaliação da economia tenha o mesmo efeito sobre o voto dos eleitores independentemente do seu nível de sofisticação política. Levando-se em conta os resultados da Tabela 1 para analisar os padrões encontrados nos gráficos acima, pode-se também afirmar que a diferença entre os mais e os menos sofisticados provavelmente não se deve ao fato de os primeiros terem atitudes mais estáveis em relação à economia. Mais ainda, também perdem força as hipóteses de que os eleitores mais sofisticados votariam menos com base na economia porque teriam visões mais nuançadas das responsabilidades sobre o desempenho econômico, ou porque se baseariam em considerações de ordem partidária ou ideológica (que foram levadas em conta nos modelos). Descartando tais hipóteses, uma conjectura possível é a de que o efeito da avaliação econômica sobre o voto seja mais forte entre os mais sofisticados porque os eleitores menos sofisticados carecem de informações mais básicas a respeito dos candidatos e da disputa eleitoral, ou porque tendem a priorizar as características pessoais dos candidatos em suas escolhas, mesmo que isso contrarie suas avaliações da economia. Tem-se, portanto, perguntas de pesquisa que requerem exames mais detidos em trabalhos futuros.

\section{Conclusões}

Assim como ocorre com outros determinantes clássicos do voto para presidente, a avaliação retrospectiva da economia não escapa de ser desigualmente utilizada pelos eleitores para basear suas escolhas de candidatos. As análises do voto em 2002 feitas aqui permitiram chegar a duas conclusões principais: (i) a avaliação retrospectiva pessoal, como perguntada na pesquisa de 2002, não apresentou efeitos sistemáticos e relevantes tanto entre os eleitores mais 
sofisticados quanto entre os eleitores menos sofisticados em qualquer uma das ondas da pesquisa; (ii) a avaliação retrospectiva sociotrópica apresentou efeitos mais consistentes sobre o voto nos quatro candidatos da disputa, mas se verificou que a magnitude de tal efeito depende do nível de sofisticação política dos respondentes, sendo maior entre os respondentes mais politicamente sofisticados, e praticamente inexistente entre os menos sofisticados.

Portanto, só foi possível falar em voto econômico com referência à avaliação do respondente sobre a situação do país, e não da própria situação pessoal. Além disso, e ainda mais importante para os propósitos do presente artigo, só foi possível falar em voto econômico ao tratar-se de eleitores mais politicamente sofisticados. Essas evidências contrariam fortemente certa crença de que, uma vez que não se mostram tão capazes de basearem-se em vínculos mais estáveis e duradouros como a preferência partidária e a auto-localização ideológica, as massas se baseariam no desempenho da economia para votar. O que se viu aqui foi que são justamente os mais sofisticados que tendem a utilizar sistematicamente a avaliação retrospectiva da economia para escolherem seus candidatos, e que não parece haver conexão muito clara entre a percepção da economia e o voto entre os eleitores menos sofisticados.

Portanto, a sofisticação política parece interferir diretamente na probabilidade de que um eleitor seja capaz de conectar seu julgamento sobre a economia com sua preferência por um ou outro candidato a presidente. Tal relação pode ter desdobramentos normativos importantes para a qualidade da representação eleitoral no país, uma vez que o eleitorado menos sofisticado nem sempre é capaz de punir ou recompensar os governantes com base no desempenho da economia, como sugerem certas versões da teoria democrática. Obviamente, não se trata de dizer que, em quaisquer circunstâncias, eleitores menos sofisticados sejam incapazes de basear suas escolhas do candidato a presidente na economia. A postura desenvolvida aqui apenas argumenta em favor da proposição de que pode ser inadequado analisar o efeito da avaliação retrospectiva da economia como se fosse um e apenas um - e geralmente forte - para o eleitorado como um todo. Vale a pena também enfatizar que as propriedades do ambiente podem afetar a conexão entre avaliação retrospectiva e voto, mas a teorização e a produção de dados empíricos sobre esse tópico ainda é muito incipiente. Uma agenda em aberto para as pesquisas sobre o tema consiste em verificar em que contextos a desigualdade de sofisticação política afeta mais a probabilidade de os eleitores votarem economicamente, e em que contextos esse efeito da sofisticação é neutralizado.

Frederico Batista Pereira (frederico.b.pereira@vanderbilt.edu) É Mestre em Ciência Política pela Universidade Federal de Minas Gerais (UFMG) e Doutorando em Ciência Política pela Vanderbilt University (EUA).

\section{Referências}

Aidt, T. 2000. Economic Voting and Information. Electoral Studies, 19(2), pp. 349-362.

Alvarez, M.; Nagler, J. 1998. When Politics and Models Collide: Estimating models of multiparty elections. American Journal of Political Science, 42(1), pp. 55-96.

Anderson, C. 2006. Economic Voting and Multilevel Governance: A comparative individual-level analysis. American Journal of Political Science, 50(2), pp. 449-463.

Arceneux, K.; Stein, R. 2006. Who is Held Responsible When Disaster Strikes? The attribution of responsibility for a natural disaster in an urban election. Journal of Urban Affairs, 28(1), pp. 43-53.

Baker, A.; Ames, B.; Rennó, L. 2006. Social Context and Campaign Volatility in New Democracies: Networks and neighborhoods in Brazil's 2002 Elections. American Journal of Political Science, 50(2), pp. 382-399. 
Baker, F. 2001. The Basics of Item Response Theory. Baltimore: ERIC Clearinghouse on Assessment and Evaluation.

Bartels, L. 1986. Uninformed Voters: Information effects in presidential elections. American Journal of Political Science, 40 (1), pp. 194-230.

Birnbaum, A. 1968. Some Latent Trait Models and Their Use in Inferring an Examinee's Ability. In F. Lord; F. Novick, eds. Statistical Theories of Mental Test Scores. Reading: Addison-Wesley.

Camargos, M. 1999. Do bolso para as urnas: a influência da economia na escolha entre Fernando Henrique e Lula nas eleições de 1998. Rio de Janeiro. Dissertação (Mestrado em Ciência Política). Instituto Universitário de Pesquisas do Rio de Janeiro.

Campbell, A.; Converse, P.; Miller, W.; Stokes, D. 1960. The American Voter. New York: John Wiley.

Carreirão, Y. 1999. Avaliação do governo e 'voto econômico'. Lua Nova, 48, pp. 213-232. 2002. Identificação ideológica e voto para presidente. Opinião Pública, 8(1), pp. 54-79.

2004. A eleição presidencial de 2002: uma análise preliminar do processo e dos resultados eleitorais. Revista de Sociologia e Política, 22, pp. 179-194.

2007. Relevant Factors for the Voting Decision in the 2002 Presidential Election: An analysis of the ESEB (Brazilian Electoral Study) Data. Brazilian Political Science Review, 1(1), p. 70-101.

Carreirão, Y.; Barbetta, P. 2004. A eleição presidencial de 2002: a decisão do voto na região da Grande São Paulo. Revista Brasileira de Ciências Sociais, 19(56), pp. 75-93.

Castro, M. 1994. Determinantes do comportamento eleitoral: a centralidade da sofisticação política. Rio de Janeiro. Tese (Doutorado em Ciência Política). Instituto Universitário de Pesquisas do Rio de Janeiro.

Converse, P. 1964. The Nature of Belief Systems in Mass Publics. In D. Apter, ed. Ideology and Discontent. New York: Free Press.

Delli Carpini, M.; Keeter, S. 1996. What Americans Know About Politics and Why It Matters. New Heaven: Yale University Press.

Dow, J.; Endersby, J. 2004. Multinomial Probit and Multinomial Logit: A comparison of choice models for voting research. Electoral Studies, 23(1), pp. 107-122.

Downs, A. 1957. An Economic Theory of Democracy. New York: Harper \& Row.

Duch, R. 2001. A Developmental Model of Heterogeneous Economic Voting in New Democracies. The American Political Science Review, 95(4), pp. 895-910.

Duch, R.; Stevenson, R. 2008. The Economic Vote: How political and economic institutions condition election results. Cambridge: Cambridge University Press.

Fiorina, M. 1981. Retrospective Voting in American National Elections. New Haven: Yale University Press.

Fuks, M.; Batista Pereira, F. 2011. Informação e conceituação: a dimensão cognitiva da desigualdade política entre jovens de Belo Horizonte. Revista Brasileira de Ciências Sociais, 26(76), pp. 123-143.

Godbout, J.; Bélanger, É. 2007. Economic Voting and Political Sophistication in the United States: A reassessment. Political Research Quarterly, 60(3), pp. 541-554.

Gomez, B.; Wilson, J.M. 2006. Cognitive Heterogeneity and Economic Voting: A comparative analysis of four democratic electorates. American Journal of Political Science, 50(1), pp. 127-145.

2008. Political Sophistication and Attributions of Blame in the Wake of Hurricane Katrina. Publius: The Journal of Federalism, 38(4), pp. 633-650.

Howell, S. 1986. Candidates and Attitudes: Revisiting the Question of Causality. The Journal of Politics, 48(2), pp. $450-464$.

Hunter, W.; Power, T. 2007. Rewarding Lula: Executive power, social policy, and the Brazilian elections of 2006. Latin American Politics and Society, 49(1), pp. 1-30.

Katz, J.; King, G. 1999. A Statistical Model for Multiparty Electoral Data. The American Political Science Review, 93(1), pp. 15-32.

Key, V.O. 1966. The Responsible Electorate: Rationality and presidential voting 1936-60. Cambridge: Harvard University Press.

King, G.; Keohane, R.; Verba, S. 1994. Designing Social Inquiry: Scientific inference in qualitative research. Princeton: Princeton University Press.

Lamounier, B. 1975. Comportamento eleitoral em São Paulo: passado e presente. InB. Lamounier; F.H. Cardoso, eds. Os partidos e as eleições no Brasil. Rio de Janeiro: Paz e Terra.

. 1980. O voto em São Paulo: 1970-1978. In B. Lamounier. Voto de desconfiança: eleições e mudança política no Brasil: 1970-1979. São Paulo: Vozes.

Lazarsfeld, P.; Berelson, B.; Gaudet, H. 1965. The People's Choice: How to voter makes up his mind in a presidential campaign. New York: Columbia University Press.

Lewis-Beck, M. 1985. Pocketbook Voting in U.S. National Election Studies: Fact or artifact? American Journal of Political Science, 29(2), pp. 348-356.

Licio, E.; Rennó, L.; Castro, H. 2009. Bolsa Família e voto na eleição presidencial de 2006: em busca do elo perdido. Opinião Pública, 15(1), pp. 31-54.

Long, S. 1997. Regression Models for Categorical and Limited Dependent Variables. London: Sage Publications. 
Luskin, R. 1987. Measuring Political Sophistication. American Journal of Political Science, 31(4), pp. 856-899. 1990. Explaining Political Sophistication. Political Behavior, 12(4), pp. 331-361.

2002. Political Psychology, Political Behavior and Politics: Questions of aggregation, causal distance and taste. In J. Kuklinski, ed. Thinking About Political Psychology. New York: Cambridge University Press.

Mendes, A.; Venturi, G. 1994. Eleição Presidencial: o Plano Real na sucessão de Itamar Franco. Opinião Pública, 2(2), pp. 59-72.

Meneguello, R. 1996. Electoral Behavior in Brazil: The 1994 presidential elections. International Social Science Journal, 147, pp. 627-641.

Mutz, D. 1993. Direct and Indirect Routes to Politicizing Personal Experience: Does knowledge make a difference? The Public Opinion Quarterly, 57(4), pp. 483-502.

Neuman, W.R. 1981. Differentiation and Integration: Two dimensions of political thinking. The American Journal of Sociology, 86(6), pp. 1236-1268.

Nicolau, J. 2007. An Analysis of the 2002 Presidential Elections Using Logistic Regression. Brazilian Political Science Review, 1(1), pp. 125-135.

Nicolau, J.; Peixoto, V. 2007. As bases municipais da votação de Lula em 2006. In J. Velloso, ed. Quem Elegeu Lula? Rio de Janeiro: Cadernos do Fórum Nacional.

Peixoto, V.; Rennó, L. 2011. Mobilidade social ascendente e voto: as eleições presidenciais de 2010 no Brasil. Opinião Pública, 17(2), pp. 304-332.

Reis, F. 1975. As eleições em Minas Gerais. In B. Lamounier; F.H. Cardoso, eds. Os partidos e as eleições no Brasil. Rio de Janeiro: Paz e Terra.

1978. Classe social e opção partidária: eleições de 1976 em Juiz de Fora. In . Os Partidos e o regime: a lógica do processo eleitoral brasileiro. São Paulo: Edições Símbolo.

1988. Identidade, política, e a teoria da escolha racional. Revista Brasileira de Ciências Sociais, 6(3), pp. 26-38.

. 1991. O tabelão e a lupa: teoria, método generalizante e idiografia no contexto brasileiro. Revista Brasileira de Ciências Sociais, 16(6), pp. 27-42.

2000. Política e racionalidade: problemas de teoria e método de uma sociologia crítica da política. Belo Horizonte: Editora UFMG.

Reis, F.; Castro, M. 1992. Regiões, classe e ideologia no processo eleitoral brasileiro. Lua Nova, 26, pp. 81-131.

Rennó, L. 2006. Os militantes são mais informados? Desigualdade e informação política nas eleições de 2002. Opinião Pública, 12(2), pp. 329-347.

2007. Desigualdade e informação política: as eleições brasileiras de 2002. Dados, 50(4), pp. 721-755.

Rennó, L.; Gramacho, W. 2010. Let's Blame Everyone: Executive and Legislative of Economic Performance in Brazil and Chile. Journal of Politics in Latin America, 2(1), pp. 53-78.

Ribeiro, E.; Carreirão, Y.; Borba, J. 2011. Sentimentos partidários e atitudes políticas entre os brasileiros. Opinião Pública, 17(2), pp. 333-368.

Robinson, W.S. 1950. Ecological Correlations and the Behavior of Individuals. American Sociological Review, 15(3), pp. 351-357.

Shikida, C.; Monasterio, L.; Araujo Jr., A.; Carraro, A.; Damé, O. 2009. 'It's the economy, companheiro!': An empirical analysis of Lula's re-election. Economics Bulletin, 29(2), pp. 977-992.

Sniderman, P.; Brody, R.; Tetlock, P. 1991. Reasoning and Choice: Explorations in Political Psychology. New York: Cambridge University Press.

Soares, G.; Terron, S. 2008. Dois Lulas: a geografia eleitoral da reeleição (explorando conceitos, métodos e técnicas de análise geoespacial). Opinião Pública, 14(2), pp. 269-301.

Trindade, H.; De Cew, J. 1978. Confrontação política e decisão eleitoral: as eleições municipais de 1976 em Caxias do Sul. In F. Reis, ed. Os partidos e o regime: a lógica do processo eleitoral brasileiro. São Paulo: Edições Símbolo.

Turgeon, M.; Rennó, L. 2010. Informação política e atitudes sobre gastos governamentais e impostos no Brasil: evidências a partir de um experimento de opinião pública. Opinião Pública, 16(1), pp. 143-159.

Weisberg, H. 1974. Models of Statistical Relationship. The American Political Science Review, 68(4), pp. 1638-1655.

Zaller, J. 1992. The Nature and Origins of Mass Opinion. New York: Cambridge University Press.

Zaller, J.; Feldman, S. 1992. A Simple Theory of Survey Response: Answering questions versus revealing preferences. American Journal of Political Science, 36(3), pp. 579-616.

Zucco, C. 2008. The President's New Constituency: Lula and the pragmatic vote in Brazils 2006 presidential elections. Journal of Latin American Studies, 40(1), pp. 29-49. 


\section{ABSTRACT}

This article discusses economic voting from the perspective of unequal political sophistication among voters. Several studies show evidence that Brazilian voters are able to connect their perceptions about the economy to their vote choice and to their evaluations of the president. This evidence is often used to support the claim that Brazilian mass electorates are capable of making reasonable choices by basing their judgments on the economy instead of paying too much attention to parties, issues, or ideological labels. This article analyzes panel survey data from Caxias do Sul and Juiz de Fora in 2002 in order to test whether the effect of retrospective economic evaluations on vote choice depends on voters' levels of political sophistication. The results show that retrospective economic evaluations tend to be quite unstable over time, and that their impact is limited to the vote choice of more sophisticated voters. Finally, the article discusses the implications of the findings and the importance of taking into account the inequality of political sophistication in understanding the dynamics of elections and public opinion in Brazil

KEYWORDS: economic voting; retrospective evaluations; political sophistication; elections; civic competence. 


\section{Apêndice}

Tabela A1 - Coeficientes e erros omitidos na Tabela 1 para o modelo de abril/maio

\begin{tabular}{|c|c|c|c|}
\hline Variável independente & Lula & Garotinho & Ciro \\
\hline Constante & $\begin{array}{c}0,91 * * \\
(0,41)\end{array}$ & $\begin{array}{c}1,88 * * * \\
(0,42)\end{array}$ & $\begin{array}{l}-0,15 \\
(0,47)\end{array}$ \\
\hline Preferência pelo PT (não=0) & $\begin{array}{c}1,61 * * * \\
(0,14)\end{array}$ & $\begin{array}{c}0,19 \\
(0,16)\end{array}$ & $\begin{array}{c}0,01 \\
(0,18)\end{array}$ \\
\hline Preferência pelo PSDB (não $=0$ ) & $\begin{array}{c}-0,91 * * \\
(0,40)\end{array}$ & $\begin{array}{c}-0,99 * * \\
(0,39)\end{array}$ & $\begin{array}{l}-0,51 \\
(0,34)\end{array}$ \\
\hline Esquerda & $\begin{array}{c}0,74 * * * \\
(0,15)\end{array}$ & $\begin{array}{c}-0,02 \\
(0,17)\end{array}$ & $\begin{array}{c}0,17 \\
(0,18)\end{array}$ \\
\hline Centro & $\begin{array}{c}-0,01 \\
(0,20)\end{array}$ & $\begin{array}{c}0,17 \\
(0,20)\end{array}$ & $\begin{array}{l}0,41^{*} \\
(0,21)\end{array}$ \\
\hline Direita & $\begin{array}{c}-0,57 * * * \\
(0,15)\end{array}$ & $\begin{array}{l}-0,27^{*} \\
(0,15)\end{array}$ & $\begin{array}{l}-0,22 \\
(0,17)\end{array}$ \\
\hline Escolaridade & $\begin{array}{l}-0,01 \\
(0,02)\end{array}$ & $\begin{array}{l}-0,02 \\
(0,02)\end{array}$ & $\begin{array}{c}0,05 * * \\
(0,02)\end{array}$ \\
\hline Sexo (Mulher=0) & $\begin{array}{c}0,36^{* * *} \\
(0,12)\end{array}$ & $\begin{array}{l}-0,09 \\
(0,13)\end{array}$ & $\begin{array}{l}-0,14 \\
(0,13)\end{array}$ \\
\hline Raça $($ Branco=1) & $\begin{array}{l}-0,24 * \\
(0,13)\end{array}$ & $\begin{array}{c}-0,39 * * * \\
(0,14)\end{array}$ & $\begin{array}{l}-0,25^{*} \\
(0,15)\end{array}$ \\
\hline Idade & $\begin{array}{c}0,00 \\
(0,00)\end{array}$ & $\begin{array}{c}-0,01^{* *} \\
(0,00)\end{array}$ & $\begin{array}{c}0,00 \\
(0,00)\end{array}$ \\
\hline Cidade (Juiz de Fora=0) & $\begin{array}{c}-0,57 * * * \\
(0,12)\end{array}$ & $\begin{array}{c}-0,68 * * * \\
(0,13)\end{array}$ & $\begin{array}{c}-0,46^{* * *} \\
(0,13)\end{array}$ \\
\hline $\begin{array}{l}\text { n } \\
\text { Log Likelihood } \\
\text { Wald Qui-quadrado (45) }\end{array}$ & & $\begin{array}{c}1524 \\
-1619,00 \\
572,15\end{array}$ & \\
\hline
\end{tabular}

$* * *$ Estatisticamente significativo a 0,01

** Estatisticamente significativo a 0,05

* Estatisticamente significativo a 0,10

Fonte: $\mathrm{O}$ autor. 
Tabela A2 - Coeficientes e erros omitidos na Tabela 1 para o modelo de setembro

\begin{tabular}{|c|c|c|c|}
\hline Variável independente & Lula & Garotinho & Ciro \\
\hline Constante & $\begin{array}{c}1,01 * * * \\
(0,33)\end{array}$ & $\begin{array}{c}1,28 * * * \\
(0,38)\end{array}$ & $\begin{array}{c}0,09 \\
(0,34)\end{array}$ \\
\hline Preferência pelo PT (não=0) & $\begin{array}{c}1,15^{* * *} \\
(0,12)\end{array}$ & $\begin{array}{l}-0,23 \\
(0,17)\end{array}$ & $\begin{array}{l}-0,18 \\
(0,14)\end{array}$ \\
\hline Preferência pelo PSDB $($ não $=0$ ) & $\begin{array}{c}-0,41 \\
(0,27)\end{array}$ & $\begin{array}{l}-0,48 \\
(0,34)\end{array}$ & $\begin{array}{l}-0,29 \\
(0,26)\end{array}$ \\
\hline Esquerda & $\begin{array}{c}0,71 * * * \\
(0,13)\end{array}$ & $\begin{array}{l}0,29 * \\
(0,17)\end{array}$ & $\begin{array}{c}0,15 \\
(0,14)\end{array}$ \\
\hline Centro & $\begin{array}{l}-0,22 \\
(0,16)\end{array}$ & $\begin{array}{c}0,24 \\
(0,19)\end{array}$ & $\begin{array}{c}0,23 \\
(0,16)\end{array}$ \\
\hline Direita & $\begin{array}{c}-0,40 * * * \\
(0,12)\end{array}$ & $\begin{array}{c}0,00 \\
(0,14)\end{array}$ & $\begin{array}{l}-0,01 \\
(0,12)\end{array}$ \\
\hline Escolaridade & $\begin{array}{c}-0,03^{*} \\
(0,02)\end{array}$ & $\begin{array}{c}-0,08 * * * \\
(0,02)\end{array}$ & $\begin{array}{c}0,02 \\
(0,02)\end{array}$ \\
\hline Sexo (Mulher $=0)$ & $\begin{array}{c}0,59 * * * \\
(0,10)\end{array}$ & $\begin{array}{c}0,33 * * * \\
(0,12)\end{array}$ & $\begin{array}{c}0,35 * * * \\
(0,10)\end{array}$ \\
\hline $\operatorname{Raça}($ Branco=1) & $\begin{array}{l}-0,13 \\
(0,10)\end{array}$ & $\begin{array}{c}-0,23^{*} \\
(0,12)\end{array}$ & $\begin{array}{c}0,16 \\
(0,11)\end{array}$ \\
\hline Idade & $\begin{array}{c}0,00 \\
(0,00)\end{array}$ & $\begin{array}{l}-0,01 \\
(0,00)\end{array}$ & $\begin{array}{c}0,00 \\
(0,00)\end{array}$ \\
\hline Cidade (Juiz de Fora $=0$ ) & $\begin{array}{c}-0,98 * * * \\
(0,10)\end{array}$ & $\begin{array}{c}-0,84 * * * \\
(0,12)\end{array}$ & $\begin{array}{c}-0,44 * * * \\
(0,10)\end{array}$ \\
\hline $\begin{array}{l}\mathrm{n} \\
\text { Log Likelihood } \\
\text { Wald Qui-quadrado (45) }\end{array}$ & & $\begin{array}{c}2493 \\
-2626,98 \\
744,78\end{array}$ & \\
\hline
\end{tabular}

*** Estatisticamente significativo a 0,01

** Estatisticamente significativo a 0,05

* Estatisticamente significativo a 0,10

Fonte: $\mathrm{O}$ autor. 
Tabela A3 - Coeficientes e erros omitidos na Tabela 1 para o modelo de outubro

\begin{tabular}{|c|c|c|c|}
\hline Variável independente & Lula & Garotinho & Ciro \\
\hline Constante & $\begin{array}{c}1,39^{* * * *} \\
(0,33)\end{array}$ & $\begin{array}{c}1,07 * * * \\
(0,37)\end{array}$ & $\begin{array}{c}-0,96^{* *} \\
(0,42)\end{array}$ \\
\hline Preferência pelo PT (não=0) & $\begin{array}{c}2,72 * * * \\
(0,18)\end{array}$ & $\begin{array}{c}1,03^{* * *} \\
(0,21)\end{array}$ & $\begin{array}{c}0,67 * * * \\
(0,23)\end{array}$ \\
\hline Preferência pelo PSDB (não = 0) & $\begin{array}{c}-1,19 * * * \\
(0,30)\end{array}$ & $\begin{array}{l}-0,29 \\
(0,29)\end{array}$ & $\begin{array}{c}-0,81 * * * \\
(0,31)\end{array}$ \\
\hline Esquerda & $\begin{array}{c}0,74 * * * \\
(0,14)\end{array}$ & $\begin{array}{c}0,38^{* *} \\
(0,16)\end{array}$ & $\begin{array}{c}0,36^{* *} \\
(0,17)\end{array}$ \\
\hline Centro & $\begin{array}{l}-0,13 \\
(0,16)\end{array}$ & $\begin{array}{c}0,00 \\
(0,18)\end{array}$ & $\begin{array}{c}0,06 \\
(0,18)\end{array}$ \\
\hline Direita & $\begin{array}{c}-0,38 * * * \\
(0,12)\end{array}$ & $\begin{array}{l}-0,02 \\
(0,13)\end{array}$ & $\begin{array}{c}-0,29 * * \\
(0,14)\end{array}$ \\
\hline Escolaridade & $\begin{array}{c}-0,04 * * \\
(0,02)\end{array}$ & $\begin{array}{c}-0,07 * * * \\
(0,02)\end{array}$ & $\begin{array}{c}0,02 \\
(0,02)\end{array}$ \\
\hline Sexo (Mulher=0) & $\begin{array}{c}0,49^{* * *} \\
(0,10)\end{array}$ & $\begin{array}{c}0,36^{* * *} \\
(0,12)\end{array}$ & $\begin{array}{c}0,30 * * \\
(0,12)\end{array}$ \\
\hline Raça $($ Branco=1) & $\begin{array}{l}-0,16 \\
(0,11)\end{array}$ & $\begin{array}{l}-0,21^{*} \\
(0,12)\end{array}$ & $\begin{array}{c}0,03 \\
(0,13)\end{array}$ \\
\hline Idade & $\begin{array}{c}0,00 \\
(0,00)\end{array}$ & $\begin{array}{c}-0,01 * * \\
(0,00)\end{array}$ & $\begin{array}{l}0,01^{*} \\
(0,00)\end{array}$ \\
\hline Cidade (Juiz de Fora $=0$ ) & $\begin{array}{c}-1,48^{* * *} \\
(0,10)\end{array}$ & $\begin{array}{c}-1,09 * * * \\
(0,11)\end{array}$ & $\begin{array}{c}-1,34 * * * \\
(0,12)\end{array}$ \\
\hline $\begin{array}{l}\text { n } \\
\text { Log Likelihood } \\
\text { Wald Qui-quadrado (45) }\end{array}$ & & $\begin{array}{c}2607 \\
-2174,00 \\
954,22 \\
\end{array}$ & \\
\hline
\end{tabular}

$* * *$ Estatisticamente significativo a 0,01

** Estatisticamente significativo a 0,05

* Estatisticamente significativo a 0,10

Fonte: $\mathrm{O}$ autor. 